University of Rhode Island

DigitalCommons@URI

Open Access Master's Theses

1993

\title{
Gender and Attitudes Toward Casual Sex as Predictors of Risky Sexual Behavior of Undergraduates
}

Donna Johnson

University of Rhode Island

Follow this and additional works at: https://digitalcommons.uri.edu/theses

\section{Recommended Citation}

Johnson, Donna, "Gender and Attitudes Toward Casual Sex as Predictors of Risky Sexual Behavior of Undergraduates" (1993). Open Access Master's Theses. Paper 1610.

https://digitalcommons.uri.edu/theses/1610

This Thesis is brought to you for free and open access by DigitalCommons@URI. It has been accepted for inclusion in Open Access Master's Theses by an authorized administrator of DigitalCommons@URI. For more information, please contact digitalcommons-group@uri.edu. 
GENDER AND ATTITUDES TOWARD CASUAL SEX

AS PREDICTORS OF

RISKY SEXUAL BEHAVIOR

OF UNDERGRADUATES

BY

DONNA JOHNSON

A THESIS SUBMITTED IN PARTIAL FULFILLMENT OF THE REQUIREMENTS FOR THE DEGREE OF MASTER OF ARTS

IN

PSYCHOLOGY 


\section{Abstract}

College men and women were compared on a number of variables concerned with risky sexual behavior, including gender and attitudes toward casual sex. MANOVA revealed that, when compared to women, men showed significantly: higher frequency of intercourse, more sex partners and higher frequency of condom use. Following a random division of the sample into two groups, a factor analysis was performed. The resulting factor structure consisted of three factors, Potential Negative Consequences, Affective Evaluation of the Environment, and perception of safety and control. Hierarchical multiple regressions showed differential predictions of risky sexual behavior by gender, attitudinal predictors and the interactions of gender and attitudes. Results support and extend previous work in this area and argue for greater attention to issues of gender for interventions with AIDS-risking behavior. Limitations to the study and future directions for research are discussed. 
Acknowledgement

The author expresses her appreciation for the guidance, encouragement and humor of Dr. Patricia J. Morokoff. She currently serves as my academic advisor, clinical supervisor and research director, and is a true role model in all positions.

I would also like to thank the other members of my committee, Dr. Joel Cohen and Dr. David Faust, for their time, effort and feedback. In addition, Dr. Brian Gladue, my undergraduate academic advisor, supervised the collection of this data and served as troubleshooter throughout my work with this project. He has been and continues to be a mentor and a friend.

For their tremendous support, I wish to thank Michelle Kemp and Linda stoler. Finally, I wish to thank my family for their love, most of all my husband, computer consultant and best friend, Gerard Poganski. 
Table of Contents

Abstract................................ . . . .

Acknowledgement............................. i i

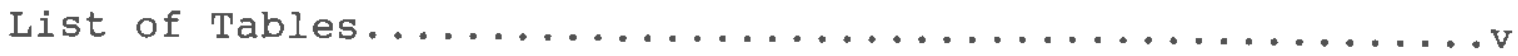

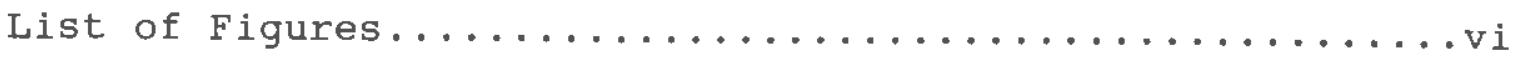

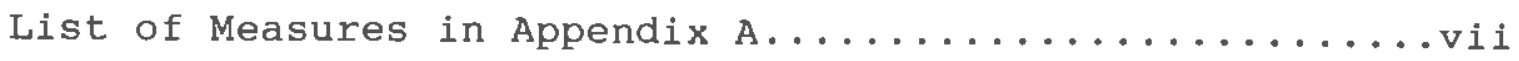
Introduction

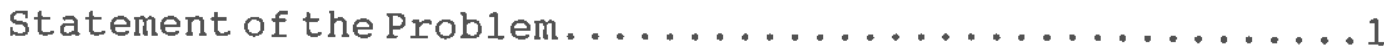

Justification and Significance of the Study..........

Gender....................................

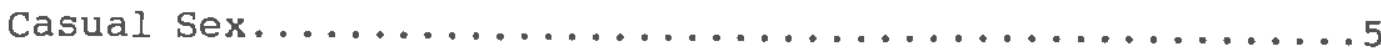

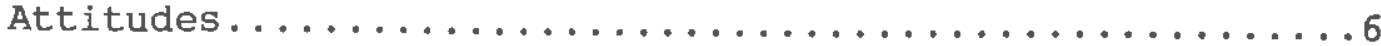

Characteristics of Risky Sexual Behavior............ 10

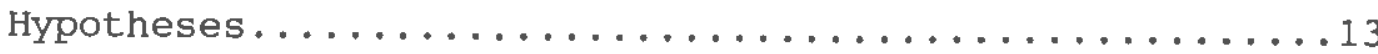
Method

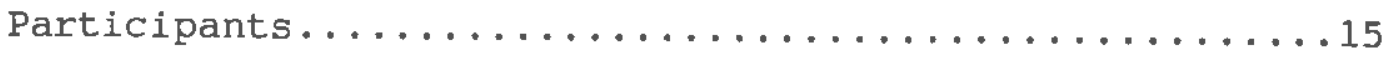

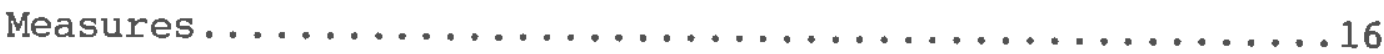

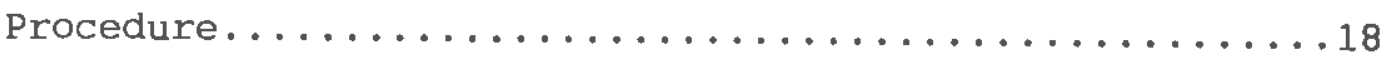

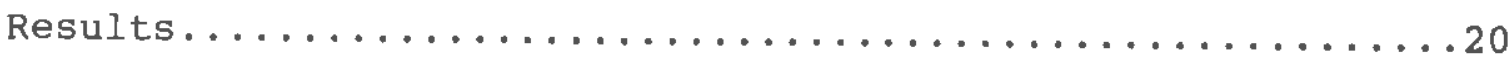

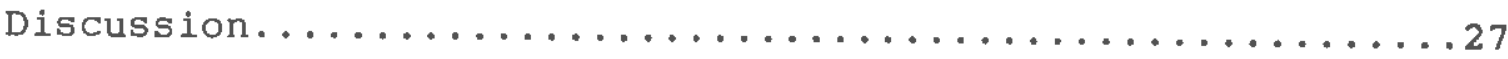

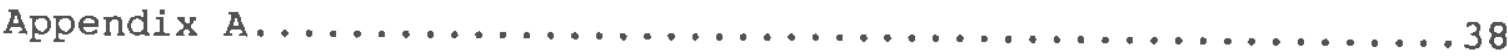

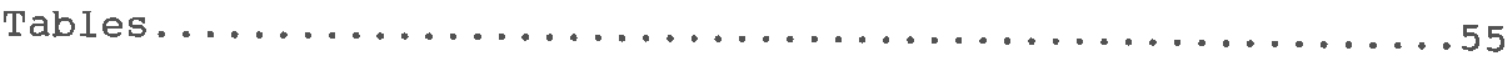

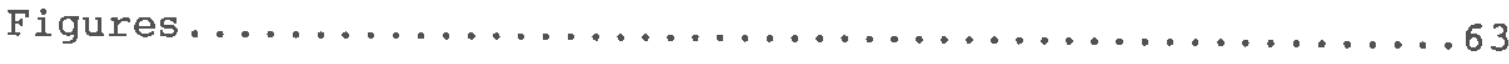

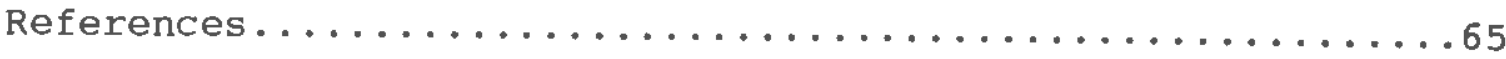


List of Tables

Table 1: Means and Standard Deviations for

Male and Female Participants................55

Table 2: Varimax Loading of Items of Attitudes

Toward Casual sex survey.................. 56

Table 3: Correlations of Risky Sexual Behaviors

and Attitudinal Predictors................ 57

Table 4: Relationships Between Risky Sexual Behaviors

and Attitudinal Predictors.................58

Table 5: Solutions to Regression Equations

for Men and Women....................... 60

Table 6: Intercorrelations of Risky

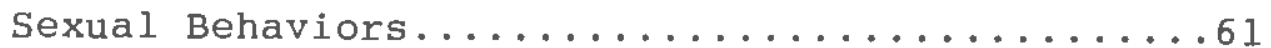

Table 7: Comparison of Research

Hypotheses and Outcomes..................662 


$$
\text { List of Figures }
$$

Figure 1: Frequency of Intercourse as Predicted by

Affective Evaluation of the Environment. . . . . . . 63

Figure 2: Number of Sex Partners as Predicted by

Potential Negative Consequences.............664

Figure 3: Number of Sex Partners as Predicted by

Perception of Safety and Control .............64 
List of Measures in Appendix A

Sexual Activity Perception and Assessment Scale..........39 Attitudes Toward Casual Sex Survey................... 50 
Gender and Attitudes Toward Casual Sex as Predictors of Risky Sexual Behavior of Undergraduates

Statement of the Problem

The purpose of the present study is to compare characteristics of risky sexual behaviors in undergraduate men and women and to predict the age at first intercourse, number of sexual partners, the frequency of intercourse and the frequency of condom use of college students based on their gender and attitudes toward casual sex. It is also of interest to determine how attitudes differentially predict behavior for men and women.

According to the Centers for Disease Control (CDC), since 1981, when the first incidences of Acquired Immune Deficiency Syndrome (AIDS) were reported in the United States, the number of cases in the U.S. has grown to 218,301 (CDC: April, 1992). Reports from the CDC of the U.S. Department of Health and Human Services indicate that over 141,200 people, totalling more than 50 percent of all cases, have died.

College students are a particularly relevant population in which to study AIDS-risking behavior. Unprotected sex has led female adolescents to have the highest rates of several sexually transmitted diseases (STD's), with prevalence rates third only to prostitutes and homosexual men (Mosher, 1985). STD's are considered surrogate biological markers for Human Immunodeficiency Virus (HIV) acquisition, highlighting the increased risk for the female college student population. The prevalence of AIDS in the adolescent population is yet 
undetermined, but 9370 cases were reported for 13-24 year-olds in the April, 1992 HIV/AIDS Surveillance Report from the CDC. Cumulative reports of diagnosis from this age group have increased 77 percent in the past three years: AIDS is now the sixth leading cause of death among 15-24 year-olds. (Kantrowitz et al., 1992). Individuals in the 20-29 age range account for 20-25\% of all reported cases, which suggests infection took place during the teenage years (Curran et al., 1988; CDC: April, 1992). College students' high level of sexual activity, coupled with the false sense of invulnerability that is characteristic of youth, may unnecessarily increase their danger of contracting the virus. Statistics suggest that three of every 1000 American college students are infected with the AIDS virus ("AIDS Virus," 1988). Although rates of infection are still low, students' behavior patterns will increasingly put them at risk as infection rates rise.

Sharing semen, blood and/or vaginal secretions with an HIV-positive person puts an individual at risk for contracting the virus. AIDS can also be transmitted through the sharing of hypodermic needles. As of April 1992, 58 percent of reported AIDS cases resulted from men having sex with men; hypodermic drug use accounted for 23 percent of reported cases (CDC: April, 1992). However, previous research has shown that few college students, approximately one percent, report the use of intravenous drugs (Strunin \& Hingson, 1987; Fisher 
\& Misovich, 1990). Though only six percent of reported AIDS cases result from heterosexual contact, this is the exposure category in which most adolescents place themselves at risk. The focus of this study will be sexual behavior. It is important to understand gender differences in risky sexual behaviors and to know what attitudes are associated with them in order to implement interventions which effectively target men and women and the various attitudes they hold.

\section{Justification for and Significance of the Study}

College is frequently the period for experimentation in a young adult's life, whether it be experimentation with illicit substances, sex and multiple sexual partners, illegal activities or simply freedom from the rules imposed upon them at home. Of special interest in this study is what determines a college student's decision to engage in risky sexual behavior.

Sex with a stranger is frequently cited as both an experience and a fantasy of college students (Person, Terestman, Myers, Goldberg, \& Salvadori, 1989). Biglan et al. (1990) found $41 \%$ of men and $28 \%$ of women reported having sex in the past year with someone they did not know well. Fisher and Misovich (1990) found $30 \%$ of men and women had sex in the past year with someone they knew moderately well; $25 \%$ had sex with someone whom they knew only slightly. The authors did not report separate percentages for men and women. Nor did Baldwin and Baldwin (1988) who found that $19 \%$ of men and women have had sex with a stranger or casual acquaintance in the past three months. 
In order to understand potential predictors of risky sexual behaviors, it is important to accurately characterize college students' sexual behaviors, especially those that put them at risk for AIDS. I will begin by discussing gender and attitudes as predictors of risky sexual behavior, then I will review literature on AIDS-risking sexual behaviors among college students, such as the age at first intercourse, the number of sexual partners, the frequency of sexual intercourse and whether condoms are used during sexual interactions.

\section{Gender}

Gender differences have been found in sexual attitudes and the practice of risky sexual behaviors. Therefore, this study will examine attitudinal predictors of AIDS-risking sexual behaviors and gender differences in these behaviors.

Wilson and Medora (1990) found that males are significantly more permissive than females in their attitudes toward premarital sex for a casually acquainted couple. Males also report fantasies of sexual intercourse with strangers twice as often as women and are significantly more accepting of extramarital sex (Wilson \& Medora, 1990). Gfellner (1988) in her study of the gender, sexual attitudes and sexual behaviors of older adolescents, stated that though adolescents approve of premarital sex in an intimate relationship, males are consistently more permissive than females.

Men also significantly differed from women in their willingness to ask a potential partner about their sexual history: $27 \%$ of the males would not ask, compared to less 
than $3 \%$ of the females. Clark (1990) also found significant gender differences between males and females regarding risky sexual behavior. In his study, $69 \%$ of males approached on campus by an opposite-sex stranger/confederate answered affirmatively to the question "Would you go to bed with me tonight?" None of the females responded affirmatively to an opposite-sex stranger/ confederate.

\section{Casual Sex}

Casual sex is defined in this study as genital intercourse with a person one does not know well, a stranger or an acquaintance. Casual sex is especially risky because the sexual history of the partner is unknown, and open communication about sexual history, means of protection (such as condoms) and birth control is less likely.

Because casual sex is so risky, studying the attitudinal predictors of its occurrence could prove to be important. For example, Potential Negative Consequences of a casual sex experience include physical harm, acquisition of a curable venereal disease, pregnancy, acquisition of an incurable venereal disease or unenjoyable sex. In the decision to engage in sexual intercourse with a person one does not know well, all of the above possibilities may be considered.

Perceived opinions of others may also influence the decision to engage in casual sex. If friends find the potential sexual partner undesirable; or, if family members feel casual sex is an irresponsible and/or immoral act, their perceived opinions may be taken into consideration and affect 
an individual's decision.

Personal knowledge or friend's knowledge of the potential sexual partner may influence the decision to engage in casual sex, and are considered in the attitudinal predictor Perception of Safety and Control. This predictor also includes questions of how important it is who controls the initial meeting and whose idea it is to have sex.

Affective Evaluation of the Environment, embodied by considerations of whether the potential partner is met in a strange or familiar locale, with friends or alone, may differentially affect the decision to engage in casual sex. Attitudes

Though attitudes have been studied for many years, there is no universally accepted definition. Various theorists define attitudes in terms of evaluation, affect, cognition and behavioral predispositions (Olson \& Zanna, 1993).

The assumption of most research concerning attitudes is that "people who hold positive attitudes should engage in behaviors that approach, support, or enhance the attitude object, and people who hold negative attitudes should engage in behaviors that avoid, oppose, or hinder the object" (Eagly \& Chaiken, 1992). The assumed relationship between attitudes and behavior has been challenged since LaPiere's (1934) landmark study which highlighted the discrepancy between stated attitudes toward a minority group and actual behaviors toward representatives of that group.

Wicker (1969), in his review article, stated "that it is 
considerably more likely that attitudes will be unrelated or only slightly related to overt behaviors." However, Schuman and Johnson (1976) reported that Wicker averaged results of 31 studies that differed vastly in terms of relevance, merit and ease of summary. In their own evaluation, the authors discuss factors that they found help to specify attitude-behavior relationships and claim that most attitude-behavior studies yield positive results.

Olson \& Zanna (1993) provided a more recent review article of this topic. The authors examined a very limited sample of articles published during the years 1989 to 1991 . Various models of the attitude-behavior relation were discussed, and possible mechanisms by which behavior affects attitudes were explored.

A comprehensive analysis of the attitude literature was recently published by Eagly \& Chaiken (1992), and an entire chapter is devoted to the relationship of attitudes and behaviors. The authors present the history of empirical studies which addressed the attitude-behavior controversy, beginning with the work of LaPiere (1934), moving to Wicker (1969), whose paper escalated the debate, and ending with current trends. Recent research has suggested methods to increase attitude-behavior correlations, including aggregating a number of specific behaviors to create a multiple-act behavioral measure, and using compatible measures of attitudes and behaviors. Early \& Chaiken also present various models of the attitude-behavior relation, including their own composite 
model and the theory of reasoned action.

Fishbein \& Ajzen's (1975) theory of reasoned action is held as a standard by many in the field of attitude-behavior research. The authors suggest that attitude toward the behavior, in combination with subjective norms, determine behavioral intentions to engage in volitional behaviors.

Volitional behavior refers to behavior under the control of intentions, voluntary behavior which people decide to perform (Eagly \& Chaiken, 1992). This definition would characterize the behaviors surveyed in this paper; that is, engaging in intercourse with one or more partners and using condoms are behaviors which individuals decide to perform.

Given background research on attitude-behavior relations, it was hypothesized that the following attitudinal factors would provide moderate predictions of subjects' participation in risky sexual behaviors.

Potential Negative Conseguences Several factors affect an individual's willingness to engage in risky sexual behavior. Surprisingly, knowledge does not appear to be one of these factors. College students appear well-informed about AIDS and behaviors that put one at risk for infection; however, recognition of high-risk behavior does not translate into the perception of one's own susceptibility (Diclemente, Forrest, \& Mickler, 1990; Edgar, Freimuth, \& Hammond, 1988; Fisher \& Misovich, 1990; Gray \& Saracino, 1989, Ishil-Kuntz, 1988; Katzman, Mulholland, \& Sutherland, 1988; Loos \& Bowd, 1989; Sunenblick, 1988; Thurman \& Franklin, 1990). 
Whereas experimentation with casual sex and multiple sexual partners is often considered a rite of passage, it is also a potentially life-threatening experience. The lack of a perceived personal threat may contribute to college students' continued involvement in risky behaviors, particularly sexual behaviors.

Perceived opinions of others Though a developing body and hormonal activity may act as stimuli, social factors also influence sexual activity. A prominent social factor in the lives of adolescents and young adults is the influence of their peers, and this appears to play an important role in sexual behavior. Adolescents more often associate to the perceived, rather than actual, sexual behavior of their peers (Cvetkovich \& Grote, 1980).

Levels of communication, connectedness and supportiveness between parents and children appear to affect age at first intercourse (Inazu \& Fox, 1980; Jessor \& Jessor, 1977). Sexually active adolescents with parents who are not available are more likely to engage in sexual risk taking and less likely to use condoms (Biglan et al., 1990). Gender of the communicating parent also affects their offspring's sexual activity: mother-daughter and mother-son interactions concerning sex frequently result in later initiation of intercourse, while father-son communication seems to result in earlier initiation (Kahn, Smith \& Roberts, 1984). Bishop and Lipsitz (1991) also found gender differences in parental influences on adolescents: over $90 \%$ of females felt their 
fathers would want them to be married prior to engaging in sexual intercourse, while only $57 \%$ of males felt this way.

Perception of Safety and Control and Affective Evaluation of the Environment It is reasonable to believe that individuals, particularly women, would consider the environment in which a potential sexual partner was encountered, whether the locale was a familiar one and/or whether friends were present and supportive. It is also believed that women, more so than men, would be concerned for their safety in a casual sex situation and would take into consideration who initiates sex and who controls the activity. Unfortunately, there is no current research on these factors. The purpose of the present study is to examine the relationship of behaviors to such perceptions.

Characteristics of Risky Sexual Behavior

Age at first intercourse The age at which men become sexually active has been reported as an average of 15.7 years (Zelnik, Kantner, \& Ford, 1981) to an average of 16.6 years (Bishop \& Lipsitz, 1991). Reports consistently show that over half of male college students are sexually active, with figures ranging from $62 \%$ (Geis \& Gerrard, 1984) to $74.5 \%$ (Bishop \& Lipsitz, 1991).

Women become sexually active at the age 16 , on the average, with reports including average ranges from 16.2 years (Zelnik et al., 1981) to 16.7 years (Bishop \& Lipsitz, 1991). From 518 (Geis \& Gerrard, 1984) to $74 \%$ (Bishop \& Lipsitz, 1991) of female college students report being sexually active. 
Number of sexual partners Sunenblick (1988) found that men had significantly more partners than women in the past year, nearly two and one-half times more partners. Among sexually active students, those with multiple sexual partners range from $8.4 \%$, who had three or more partners in the past three months (Baldwin \& Baldwin, 1988), to those who had more than two sexual partners in the past year: $21.2 \%$ (DeBuono et al., 1990) to $26 \%$ (Sunenblick, 1988) of women and 398 (Biglan et al., 1990) to $50 \%$ (Sunenblick, 1988) of men. Diclemente et al. (1990) found $9 \%$ of men and women reported five or more partners in the past year. Bishop and Lipsitz (1990) found in their sample of 273 college students that 24.68 of males and $21.6 \%$ of females had seven or more sexual partners during a time period which was, for most subjects, two and one-half years.

Frequency of intercourse Carroll (1991) found $47.0 \%$ of male college students engaged in sex once a week or more. Bishop and Lipsitz (1991) found that the greatest percentage of male college students in their study, $36.0 \%$, had engaged in sexual intercourse more than 50 times during their lifetime. Women exhibit similar histories and patterns of activity in these studies. Carroll (1991) found that 52.7\% of female college students engaged in sex once a week or more. When asked about past sexual experience, 45.98 of female college students claimed to have engaged in sexual intercourse more than 50 times (Bishop \& Lipsitz, 1991).

Frequency of condom use college students' reports of 
condom use range from $37 \%$ who never use condoms (DiClemente et al., 1990) to $66 \%$ who claim to use condoms less than half the time, to $59.9 \%$ who claim they use condoms all or most of the time (Severn, 1990). Carroll (1991) found that $32.2 \%$ of male college students reported using a condom during every or almost every sexual interaction. When asked if they used a condom during their last intercourse, $36.8 \%$ of men surveyed responded affirmatively (Bishop \& Lipsitz, 1990).

Women report similar patterns of condom use. In a study by Carroll (1991), $30.5 \%$ of female college students reported using a condom during every or almost every sexual interaction. Bishop and Lipsitz (1990) found that $21.8 \%$ of women claimed to have used a condom during their last intercourse. Clearly, the population of college students is utilizing condoms during only half of their sexual interactions, if that.

Age appears to be the most important demographic predictor of contraceptive use; however, the best predictor of current use is past use, as well as previous pregnancy (Zelnik et al., 1981). Sex guilt and frequency of intercourse are two variables which influence women's use of contraception, while men's use is predicted by variables such as knowledge of birth control, self-esteem and relationship commitment (Geis \& Gerrard, 1984). Sack et al. (1985), in their discriminant analysis approach to premarital contraceptive use, found that the largest coefficient to separate reliable users of birth control from other users was the number of close friends 
thought to be using contraception.

Awareness of a partner's status can facilitate appropriate protection, such as using a condom, in a sexual interaction. However, casual sex does not foster a safe, secure environment for intimate communication. Though one is more likely to use effective contraception when supported and encouraged by one's partner (Whitley \& Hern, 1991; Spees, 1987), when in a casual sex situation, individuals most likely do not know their partner well enough to feel supported and encouraged by them, and thus often fail to address the need for protection from exchanging semen and vaginal fluid. The use of contraception is different in short-term and longterm relationships (Fisher et al., 1979; Foreit \& Foreit, 1978), a particularly relevant factor when studying individuals' willingness to engage in casual sex.

The hypotheses are divided by gender, based on previous literature which suggests that attitudes, especially those concerning the relationship, are more significant predictors of sexual behavior for women than men (Morokoff, 1990).

Also, women, more so than men, suffer the potential adverse consequences of casual sex, such as physical assault and pregnancy. Therefore, it seemed likely that women's sexual behavior would be more affected by issues presented in the proposed factors, including knowledge of the potential casual sex partner and the possibilities of disease or harm. Research Hypotheses

1. Men will have more sexual partners than women. 
2. Men will engage in intercourse more frequently than women.

3. Men will use condoms less often than women.

4. Potential Negative Consequences of casual sex will be negatively related to number of sexual partners for women, but not for men.

5. Potential Negative Consequences of casual sex will be negatively related to frequency of intercourse for women, but not for men.

6. Potential Negative Consequences of casual sex will be positively related to frequency of condom use for women, but not for men.

7. Affective Evaluation Environment in which casual sex is considered will be positively related to the number of sexual partners for women, but not for men.

8. Affective Evaluation of the Environment will be positively related to frequency of intercourse for women, but not for men.

9. Affective Evaluation of the Environment will be negatively related to frequency of condom use for women, but not for men.

10. Perceived Opinions of Others toward casual sex will be negatively related to number of sexual partners for women, but not for men.

11. Perceived Opinions of Others will be negatively related to frequency of intercourse for women, but not for men.

12. Perceived Opinions of Others will be positively related 
to condom use for women, but not for men.

13. Perception of Safety and Control associated with casual sex will be positively related to number of sexual partners for women, but not for men.

14. Perception of Safety and Control associated with casual sex will be positively related to frequency of intercourse for women, but not for men.

15. Perception of Safety and Control associated with casual sex will be positively related to frequency of condom use for women, but not for men.

16. There will be a negative relationship between number of sexual partners and frequency of condom use.

17. There will be a negative relationship between frequency of intercourse and frequency of condom use.

\section{Method}

The objective of the current investigation is to compare risky sexual behaviors in undergraduate men and women and to determine the relationship between attitudes toward casual sex and risky sexual behavior in college students. Risky sexual behavior will be defined as age at first intercourse, frequency of intercourse, number of sex partners and frequency of condom use (Baldwin \& Baldwin, 1988).

\section{Participants}

Among respondents, 310 were men and 346 were women. Participants were required to be 18 years of age or older. The age of respondents ranged from 18 to 43 years, with a mean of 20 years and a median of 19 years. For men, ages ranged 
from 18 to 39, with a mean of 20 years and a median of 19 years. Women ranged in age from 18 to 43 years, with a mean of 20 years and a median of 19 years.

Students were recruited for participation from introductory psychology courses where instructors informed class members that they could earn credit by enrolling in an experiment. Students signed up to participate in the study on posted rosters on a bulletin board outside the office of the Psychology Department. Each roster listed the name and principal investigator of the study; the location, date and time of the experiment; and, the number of credits the student would receive. The rosters stated that participants must be 18 years of age and have a form of identification present at the time of the session.

Measures

Demographic information and sexual history Respondents were asked to indicate their age and gender as well as provide information on their sexual history. They were asked to report the number of intimate relationships in which they had been involved, their frequency of intercourse and frequency of masturbation during the past year and lifetime number of sexual partners (refer to Appendix A: Sexual Activity Perception and Assessment Scale).

Contraceptive Use Respondents indicated whether they and/or their partner used each of several contraceptive methods and how often the method was used. Contraceptive methods assessed were birth control pills, condoms, diaphragm, 
intrauterine device (IUD), sterilization, sponge, withdrawal, rhythm and foam (refer to Sexual Activity Perception and Assessment Scale, Appendix A).

Attitudes Toward Casual Sex, a survey of 25 items created by the investigator, covered several hypothesized factors involved in deciding to engage in casual sex, including potential negative consequences of casual sex; affective evaluation of the environment in which casual sex is considered; perceived opinions of family and peers concerning participation in casual sex; and, perception of safety and control of the casual sex situation. Potential Negative Consequences included the possibilities of physical harm, such as non-sexual assault; venereal disease, either curable or incurable; pregnancy; and, unenjoyable sex. Responses were given on a ten-point likert scale which ranged from 0 , "NOT AT ALL CONCERNED" to 9, "EXTREMELY CONCERNED" (refer to Appendix A, Attitudes Toward Casual Sex Survey: questions 11, 12, 13, 14, 16). Also measured on a ten-point Likert scale, Perceived opinions of Others addressed the possibilities that peers would find the hypothetical sexual partner undesirable, and/or family would find the subject's behavior irresponsible and/or immoral. Responses ranged from 0, "NOT AT ALL CONCERNED" to 9, "EXTREMEly CONCERNED" (refer to Appendix A, Attitudes Toward Casual Sex Survey: questions 15, 17, 18) .

Responses concerning Affective Evaluation of the Environment and Perception of Safety and Control were given on a ten-point Likert scale which ranged from 0 , "NOT AT ALL 
IMPORTANT" to 9, "EXTREMELY IMPORTANT." Knowledge of the person, either by the subject or his/her friends was an issue of Perception of Safety and Control, as was who initiated sexual activity, the subject or his/her hypothetical partner (refer to Appendix A, Attitudes Toward Casual Sex Survey: questions 1, 2, 3, 8, 9, 10). Affective Evaluation of the Environment included items which addressed where the subject met his/her hypothetical partner, a familiar or strange locale, and whether the subject was alone or with friends during the encounter (refer to Appendix A, Attitudes Toward Casual Sex Survey: questions $4,5,6,7$ ) .

\section{Procedure}

Data were previously collected by the investigator during the years 1988-1989 at North Dakota State University. Two women and one man were trained to administer the survey. The individual researcher conducted the session in a lecture hall or classroom to a group ranging in size from 5 to 20 persons. Prior to the students arriving, specific instructions concerning the computer-coded response sheets, such as how to enter and code the birth date, were written on the board. Once the students arrived, they were instructed to sit with an empty seat between each person to insure privacy. The researcher then read an explanation of the experiment from a script. Participants were asked not to put any identifying information on either the surveys or response sheets, and the subject number written at the top of each form was explained as an anonymous crosscheck for keeping together all forms from 
an individual. Once the sexual content of the experiment was explained, any student unwilling to complete the survey was invited to leave. If a student so chose, the experimenter stepped into the hallway with the student, asked him/her to complete an informed consent form, and explained that credit would be given for their time and willingness to consider participation. Only one student of 656 refused to complete the surveys. When finished, students laid the completed surveys in a stack on a table that was located several feet from the researcher. On their way from the room, they were thanked and invited to address any questions or concerns to Dr. Brian Gladue. His name, campus address and phone number were listed on the informed consent form, and students were invited to take an extra copy with them for their records. Completed surveys from 656 students were ultimately gathered, 310 men and 346 women. 
Comparison of Men and Women for Risky Sexual Behaviors

A one-way multivariate analysis of variance was performed to compare men and women on the four dependent variables: age at first intercourse, frequency of intercourse, number of sex partners and frequency of condom use. Responses to questions assessing frequency of intercourse and frequency of condom use were recoded in order to maintain consistency of meaning. The analysis revealed a significant effect for gender, $=.84$, $\underline{F}(4,483)=22.28, \underline{p}<.001$.

Follow-up univariate tests found significant effects of gender for three dependent variables: frequency of intercourse, $\underline{F}(1,486)=4.70, \underline{p}<.05$; number of sex partners, $\underline{F}(1,486)=6.46, \underline{p}<.05 ;$ and, frequency of condom use, $\underline{F}(1$, $486)=71.77, \mathrm{p}<.001$. Examination of Table 1 indicates that reported age at first intercourse is lower for men, but not significantly so. Men reported higher numbers of sex partners and higher frequencies of condom use than women reported. However, women reported higher frequencies of intercourse. Principal Components Extraction on Attitudinal Predictors

Principal components extraction with varimax rotation was performed on 18 items of the Attitudes Toward Casual Sex Survey. In order to confirm the factor structure on a second sample, a random numbers table was generated and used to split the sample into two groups. Sample $1, \underline{N}=328$, consisted of 153 men and 175 women. Sample $2, \underline{N}=328$, consisted of 164 men and 164 women. 
For Sample 1, five factors emerged with eigenvalues greater than 1. Together, these factors accounted for 638 of the variance. All items loaded strongly (.40 or higher). The number of components to be retained was determined by examination of the eigenvalues and the Scree Test (Cattell, 1986). Two of the variables, items 3 and 4 , were complex. Item 16 did not load on any factor. Factors 4 and 5 consisted of only two variables each, items 17 and 18 , and items 10 and 15, respectively. Based on a desire to perform a confirmatory analysis, rather than a second, free-floating exploratory analysis, these items were eliminated prior to the factor analysis on Sample 2 (Guadagnoli \& Velicer, 1988; Velicer \& Fava, 1993).

Principal components extraction for Sample 2 was performed on 12 items of the survey and was limited to three factors. The factors which emerged replicated those found in the initial analysis. Therefore, it was decided to use a three-factor solution. Composite scales were created by adding together items loading on the same factor. Factors and the loadings of each item may be found in Table 2 .

The first factor, labeled Potential Negative Consequences, consisted of four items that reflected possible effects of having casual sex, including assault, pregnancy and sexually transmitted diseases (refer to Appendix A, Attitudes Toward Casual Sex Survey: questions 11, 12, 13, 14). Factor 2, named Affective Evaluation of the Environment, indicated the situation in which a potential casual sex 
partner may be met: alone, with friends, in a strange environment/locale (refer to Appendix A, Attitudes Toward Casual Sex Survey: questions 5, 6, 7). Finally, factor three, Perception of Safety and Control, reflected possible issues in making a decision to engage in casual sex: knowledge of the potential partner, initiation of the idea to have sex and control of the situation (refer to Appendix A, Attitudes Toward Casual Sex Survey: 1, 2, 8, 9).

Regression Analyses of Attitudes

\section{as Predictors of Risky Sexual Behavior}

Correlations between dependent variables and attitudinal factors were calculated separately for men and women. The correlation matrix is presented in Table 3. For women, Potential Negative Consequences was significantly correlated with number of sex partners, indicating that, as number of sex partners increased, so did the concern attributed to potential Negative Consequences of casual sex. Two significant correlations were found for men. First, frequency of intercourse was significantly correlated with Affective Evaluation of the Environment, meaning that as frequency of intercourse increased, so did the importance of Affective Evaluation of the Environment in which casual sex is considered. Finally, for men, number of sex partners and Perception of Safety and Control were significantly correlated; as number of sex partners increased, importance of Perception of Safety and Control also increased.

Hierarchical multiple regression analyses were conducted 
for the four dependent variables. This was done in order to examine the degree to which gender and the orthogonal attitudinal predictors accounted for independent variance in risky sexual behavior and the degree to which there were sex differences in the relationships. As the resulting factor structure was comparable, regressions were conducted on the two samples collapsed. Gender was entered first, followed by the attitudinal factor and the interaction of gender and the attitudinal factor. The results of the 12 regressions are presented in Table 4 .

Age at first intercourse. Three regression analyses were conducted, one for each of the attitudinal predictors. Gender was entered first, followed by the attitudinal predictor, and finally the interaction between gender and the attitudinal predictor. No significant predictors were found.

Frequency of intercourse. Gender was hierarchically entered first. Frequency of intercourse was not predicted by gender, potential Negative Consequences or its interaction with gender. When gender and Affective Evaluation of the Environment were entered, Affective Evaluation of the Environment was a significant predictor of frequency of intercourse. With two variables in the equation, the regression had an $\mathrm{R}=.08$, accounting for 18 of the variance, $\underline{F}(2,640)=4.08, \underline{p}<.05$.

When gender, Affective Evaluation of the Environment and the interaction of the two variables were entered into the regression equation, both Affective Evaluation of the 
Environment and the interaction were significant predictors of frequency of intercourse. The regression, with three variables in the equation, had an $R=.12$, accounting for $1 \%$ of the variance, $\underline{F}(3,639)=3.00, \underline{p}<.05$. This indicated that, for men, as importance of Affective Evaluation of the Environment in a casual sex situation increased, frequency of intercourse decreased. The opposite was true for women: as importance of Affective Evaluation of the Environment in a casual sex situation increased, frequency of intercourse increased (see Figure 1).

Perception of safety and Control and its interaction with gender did not predict frequency of intercourse.

Number of Sex Partners. Gender was hierarchically entered first. A significant effect of gender, indicating that men had higher number of sex partners, was found: $R=$ .14 , accounting for 18 of the variance, $\underline{F}(1,641)=13.44$, $\mathrm{p}<.001$.

Number of sex partners was predicted by potential Negative Consequences after variance because of gender was taken into account. The regression, with two variables in the equation, had an $\mathrm{R}=.18$, accounting for $2 \%$ of the variance, $F(2,640)=10.72, \underline{p}=.001$, indicating that, for men and women, as concern for Potential Negative Consequences of a casual sex situation increased, so did number of sex partners. The interaction between gender and potential Negative Consequences was not significant (see Figure 2).

Affective Evaluation of the Environment and its 
interaction with gender did not predict number of sex partners, though the variables approached significance.

When gender and Perception of Safety and control were entered, Perception of Safety and Control was a significant predictor of number of sex partners. With two variables in the equation, the regression had an $\mathrm{R}=.17$, accounting for 28 of the variance, $\underline{\mathrm{F}}(2,638)=9.56, \mathrm{p}<.001$. For men and women, as the importance of Perception of Safety and Control in a casual sex situation increased, the number of sex partners decreased. The interaction between gender and Perception of Safety and Control was not significant (see Figure 3).

Frequency of Condom Use. Gender was hierarchically entered first. A significant effect of gender, indicating that men had higher frequencies of condom use, was found, $\mathrm{R}=$ $.33, \underline{E}(1,642)=78.66, \underline{\mathrm{p}}<.001$, accounting for 38 of the variance.

Frequency of condom use was not predicted by Potential Negative Consequences or its interaction with gender after variance because of gender was taken into account.

Similarly, Affective Evaluation of the Environment and its interaction with gender did not predict frequency of condom use.

Finally, Perception of Safety and Control and its interaction with gender did not predict frequency of condom use.

Regression equations of significant predictors were 
solved separately for men and women. The results may be found in Table 5 and Figures 1-3.

Neither of the two hypothesized intercorrelations between dependent variables was found: number of sex partners and frequency of condom use were positively correlated, $\underline{\underline{r}}=.2273$, $\underline{p}<.001$. The correlation between frequency of intercourse and frequency of condom use was also positive, $\underline{\underline{r}}=.2336, \underline{\mathrm{p}}<$ .001 (refer to Table 6). 


\section{Discussion}

The purpose of the current study was to determine if the hypothesized attitudes toward casual sex successfully predicted risky sexual behaviors of college students, and to determine if the predictions were different for men and women. A number of reported differences in attitudes and behaviors between college men and women were identified.

As hypothesized, men reported having significantly more sex partners than women. However, women reported higher frequencies of intercourse than men, and men reported higher frequencies of condom use, two results which contradicted hypotheses.

In her study of first-year college students, Sunenblick (1988) found that men reported two and one-half times the number of sex partners that women reported. The differences in the current study are minimal. However, it may be possible that men in the current study had sex with women from populations other than college students, such as high school students and/or prostitutes.

Clark (1990) found that male college students were more willing than female college students to engage in casual sex. Assuming that the willingness translated into behavior, men would have to seek partners other than their fellow college students.

The same may be true in this study: men engaged in sexual intercourse with women who were not college students, producing discrepancies between men and women in self reports 
of frequency of intercourse and number of sex partners.

In this study, women reported higher frequencies of intercourse than men reported. This may imply that women engaged in more frequent intercourse in the context of relationships, while men sought more partners from groups other than women college students.

However, it is unlikely that women engaged in intercourse with men not represented in the sample, while men selected sex partners from populations other than fellow college students. A more likely possibility is that men, women or both men and women provided biased reports of their sexual activity.

Men's higher frequency of condom use may be explained by the fact that condoms are a male contraceptive; women using birth control may be more likely to report the use of birth control pills or the diaphragm, rather than condoms. Again, this explanation relies on the assumption that the men's partners are drawn from populations other than college students.

The factors extracted from the Attitudes Toward Casual Sex Survey met with the initial conceptualization, and were based on variables entered and variables not entered. For example, the survey did not assess relationship status; anticipated reactions of partners; individual history, including possible trauma; or, situational issues that may affect attitudes toward casual sex.

of variables entered, most items loaded as expected. One item did not load, and two items were complex. Also, one 
proposed factor, Perceived Opinions of others, did not have an adequate number of items load for inclusion, though the items expected to load did.

Overall, for the 36 regression equations that were calculated, six of the equations were significant. In each case, the significant results accounted for only $1-38$ of the variance. Therefore, attitudes studied were either nonsignificant predictors, or statistically significant predictors which accounted for only a small portion of the variance.

Thus, an important finding of this study is that attitudes toward casual sex are not meaningful predictors of individuals' choices concerning their sexual relationships. This suggests that other variables may be more meaningful predictors.

The following discussion presents the significant results found in the current study, and mentions variables studied in other research which may prove to be better predictors of risky sexual behavior.

Age at first intercourse was not predicted by gender or the attitudinal predictors, a finding which is consistent with previous research. Udry \& Billy (1987) found that for women, age at first intercourse was predicted by age, same-sex friends' sexual behavior, opposite-sex intercourse behavior, school performance, deviant behavior index and participants' intention to have sex. For men, age at first intercourse was predicted by intention to have sex and popularity with the 
opposite sex.

Morokoff (1990) summarized factors affecting the transition to sexual activity as biological pressures, peer/cultural influences, increased pressure from intimate partner, lessened parental restrictions and socioeconomic status. Because this study looked at attitudinal predictors, none of these variables were included in the current attempt to predict age at first intercourse.

It had been hypothesized that, for women, frequency of intercourse would be predicted by Potential Negative Consequences, Affective Evaluation of the Environment, and Perception of Safety and Control. None of the attitudinal predictors were hypothesized to predict frequency of intercourse for men.

Frequency of intercourse was predicted by Affective Evaluation of the Environment and its interaction with gender. As men attributed more importance to the context in which a casual sex partner was met, frequency of intercourse decreased. The opposite was true for women: as importance of Affective Evaluation of the Environment increased, so did frequency of intercourse. However, Affective Evaluation of the Environment was not a significant predictor of frequency of intercourse when women alone were studied.

Others have found perceived mutual love and communication about the sexual relationship to predict frequency of intercourse while commitment did not (Jorgensen, King \& Torrey, 1980). However, neither of these variables is an 
attitude and thus is not included in Affective Evaluation of the Environment. Affective Evaluation of the Environment addresses the importance of context, whether the subject is alone or with friends when the potential casual sex partner is met and where the meeting takes place, such as a strange location.

Perhaps perceived accuracy in Affective Evaluation of the Environment empowers an individual in his/her choices concerning sexual behavior, including frequency of intercourse. Morokoff (1990) stated that frequency of intercourse was predicted by the female partner's power, defined as the ultimate say in the sexual relationship. If the frequency of intercourse data are approached from this perspective, the results are congruent: women who consider Affective Evaluation of the Environment important may feel empowered through evaluating the context and choose to have intercourse more frequently. This possibility relies on the relationship between Affective Evaluation of the Environment and empowerment, which was not assessed in this study and would require further elaboration.

Another possibility is that frequency of intercourse is more determined by men, as initiators of sexual activity. In this scenario, women's attitudes concerning casual sex do not predict behavior. Stronger predictors may be issues concerning the relationship.

Consider Zelnik \& Shah (1983) who found that, at first intercourse, women were more often in a committed relationship 
while men were more often in a casual relationship. It is possible that questions about the importance of Affective Evaluation of the Environment were perceived as questions concerning the beginning of a potential relationship, the meeting of a new partner. If so, the implication is that Affective Evaluation of the Environment is an issue of the relationship, and as such it may be predictive of women's sexual behavior. Again, this hypothesis would require clarification and confirmation that is beyond the scope of this study.

For both men and women, as the concern for potential Negative Consequences of Casual Sex increased, so did the number of sex partners. Alternately stated, as number of sex partners increased, so did concern for potential Negative Consequences of casual sex. It appears that the subjects were concerned, but not deterred from risky sexual behavior.

However, as importance of perception of Safety and Control increased the number of sex partners decreased. This was true for both men and women. Clark (1990) stated that he felt women's unwillingness to engage in casual sex was not related to concern for safety. However, the author controlled for safety concerns in a rather equivocal manner: confederates asked the subject, a friend, if he/she would like to have sex with an as yet unknown friend of the confederate, a "really nice person." Promotion of a potential casual sex partner by a mutual friend would not seem to completely eradicate safety concerns. 
Possibly Clark's definition of safety concerns includes aspects of Potential Negative Consequences and Perception of Safety and control, two factors which when defined separately in the current study, differentially predict risky sexual behavior, specifically number of sex partners.

Number of sex partners may have been predicted in a way such that concern was expressed but not integrated. That is, subjects who had more sex partners were aware of Potential Negative Consequences of casual sex, were able to accurately express their concern but were unable to implement that concern in their own behavior. As stated above, the men and women were concerned, but not deterred.

Alcohol consumption, an interesting variable of relevance to the lives of most college students, was found by Fisher \& Misovich (1990) to be significantly correlated to number of sex partners, number of sex partners known moderately well and number of sex partners known slightly well. Also, alcohol consumption has been found to predict risky sexual behavior in women (Harlow, Grimley, Quina \& Morokoff, 1992). Though not assessed in the current survey, in future research alcohol consumption should continue to be studied as a predictor of risky sexual behavior of men and women.

Potential Negative Consequences, Affective Evaluation of the Environment, and Perception of Safety and Control were hypothesized to predict frequency of condom use for women, while none of the factors were hypothesized to predict frequency of condom use for men. Zelnik, Kanter \& Ford (1981) 
found age at first intercourse to be the only demographic variable to predict contraceptive use.

Sex guilt (Geis \& Gerrard, 1984) has been found to predict contraceptive use for women. Men's contraceptive use has been predicted by locus of control, relationship commitment, contraceptive knowledge, self-esteem and religious affiliation (Geis \& Gerrard, 1984).

Jorgensen, King \& Torrey (1980) stated that a woman's power in the relationship and in contraceptive decision making predicted contraceptive use. This finding is similar to one presented by Morokoff (1990), who found frequency of intercourse to be predicted by the female partner's power in the relationship.

None of the above stated variables were included in the current study, which attempted to predict frequency of condom use rather than general contraceptive use. The only significant predictor of frequency of condom use was gender; the proposed attitudes did not predict frequency of condom use.

It may be that condoms, as a male method of birth control, will continue to be most consistently predicted by gender. However, if women increasingly carry condoms and ask their partners to use them, predictors other than gender may emerge. In addition, locus of control, self-esteem, and other predictors of general contraceptive use may also be predictors of use of specific birth control methods, such as condoms. This possibility should be explored in future research. 
Contrary to a stated hypothesis, frequency of intercourse and frequency of condom use were positively related. Higher frequency of intercourse may imply involvement in a relationship, which may provide the basis for consistent sexual activity. If intercourse frequency is high due to involvement in a relationship, the basis for expecting sexual activity and planning contraception is more likely, possibly making frequency of condom use higher.

Again, contrary to a stated hypothesis, there was a positive relationship between number of sex partners and condom use, indicating that as number of sex partners increased so did frequency of condom use. This relationship may be related to the positive relationship between frequency of intercourse and frequency of condom use. That is, an increase in number of sex partners is related to an increase in frequency of intercourse, which, in turn is related to an increase in the frequency of condom use.

This possibility is supported by the significant, positive correlation of number of sex partners and frequency of intercourse, which indicated that as number of sex partners increased, so did frequency of intercourse.

Implications for future research begin with the results of this study. Attitudes proved to be weak predictors, accounting for $1-3 \%$ of the variance. These results, taken in consideration with the work of others (Morokoff et al., 1992) imply that different approaches must be sought in the prediction of risky sexual behaviors. 
It has been suggested that aggregating several behaviors to create a multiple-act measure and using compatible measures of attitudes and behaviors increase correlations of attitudes and behaviors (Eagly \& Chaiken, 1992). If these recommendations can be implemented in a way which increases the amount of variance explained, a more thorough exploration of the underlying beliefs concerning casual sex, perhaps sex in general, should be investigated.

Specific to this study of attitudes toward casual sex are questions concerning the factors. How does the importance of Affective Evaluation of the Environment differentially affect the behavior of men and women? Also, for both men and women, concern for Potential Negative Conseguences of casual sex was positively related to number of sex partners, a result that requires a closer look.

Finally if gender truly differentiates both attitudes and behavior, interventions concerning safer sex practices must be planned and presented in a manner that is appropriate and relevant for each gender.

There are several limitations to the study. The measures used were not perfect for the constructs studied. Questionnaire measures were developed for this study; therefore, reliability and validity have not been assessed previously. At the time the study was initiated, there was not an existing survey which addressed factors involved in an individual's decision to engage in risky sexual behavior.

It would be beneficial to create and implement other 
measures of the same constructs in order to facilitate measurement of test-retest reliability and other psychometric properties.

A confirmatory factor analysis of the current attitudinal predictors should be performed with structural analysis, which uses principles beyond the scope of this study.

Another limitation is the fact that behavioral measures of attitudes do not exist. Nor would assessment of attitudes toward casual sex be conducive to observation for measurement of attitude-behavior consistency. Means by which to improve accuracy of self-reports should be sought.

The participant sample may have been biased (Morokoff, 1986). However, subjects were not aware this was a study of sexuality. Another limitation is that the majority of subjects were first-year students enrolled in an introductory psychology course at a midwestern university, which limits generalizability to other populations. For example, people of color and individuals at high risk for contracting AIDS were not represented.

Finally, the data is based on the self-report of adolescents during the years 1988-1989. AIDS and the related area of concern, risky sexual behavior, was not as common a topic several years ago as it is now. This study analyzes attitudes and behaviors during the years 1988-1990 from the perspective of AIDS awareness in 1992. 
Appendix A 


\author{
"SCENARIOS": \\ SEXUAL ACTIVITY PERCEPTION AND ASSESSMENT SCALE
}

\title{
General Instructions
}

A major area of interest in our society is the different attitudes toward situations involving sexual interactions. As part of a research Program in Human sexuality at NDSU, we hope to expand our understanding of this particular and important area of human behavior. This questionnaire contains items regarding personal experiences and attitudes concerning sexuality, and certain sexual scenarios.

Please note: your responses to this questionnaire will be held in strict confidence. In addition, to preserve your right to privacy,

DO NOT MARK YOUR NAME OR IDENTIFICATION ANYWHERE ON THIS QUESTIONNAIRE.

It is not neccesary to know who you are; only your experiences and attitudes are important for the purposes of this research. It is hoped that, by your cooperation and the assistance of others like you, we, as a society, may gain a better understanding about this important area of human society and behavior. Completing this questionnaire is voluntary.

This survey contains items which make reference to human sexuality and sexual behavior. If you do not desire to be exposed to such statements or remarks, please do not go any further. In this case, return the questionnaire to the investigator.

If you decide to participate in this survey, please answer all questions honestly and the best of your ability. It is important that we have truthful information.

Remember: All information is kept in strict confidence.

DO NOT PUT YOUR NAME OR IDENTIFICATION ANYWHERE ON THIS QUESTIONNAIRE OR ON THE RESPONSE SHEET. 
Thank you for agreeing to participate in this research.

Completing the entire questionnaire should take about one hour.

PLEASE MARK ALL YOUR RESPONSES ON THE COMPUTER

RESPONSE SHEETS AS INSTRUCTED ON THE QUESTIONNAIRE.

If you have any questions about the survey or about how or where to mark your responses, please contact the experimenter.

PLEASE DO NOT MARK OR WRITE ON THIS QUESTIONNAIRE.

PLACE ALL RESPONSES ON THE COMPUTE SCORING SHEETS.

You may turn the page and begin. Again, please answer all questions as honestly and as accurately as possible. 
Please answer each of the following questions as accurately and as honestly as possible. Remember, all information is held in strict confidence.

1. Please indicate your age category:
A. $18-19$
F. $31-35$
B. $20-21$
G. $36-40$
C. 22-23
H. $41-45$
D. $24-25$
I. $\quad 46-50$
E. $26-30$
J. older than 50 years

2. Gender:
A. Male
B. Female

3. At what age did you begin one-on-one dating (Not in a group of friends)?
A. age 12 or younger
B. 13
C. 14
D. 15
E. 16
F. 17
G. 18
H. 19
I. 20
J. age 21 or older

4. At what age did you first go steady (Consistent dating of one person only)?
A. age 12 or younger
B. 13
C. 14
D. 15
E. 16
F. 17
G. 18
H. 19
I. 20
J. age 21 or older 
5. currently (DURING THE PAST YEAR), I have dated (number of dates, not necessarily with different people):
A. not at all
B. once
C. twice
D. 3-4 times
E. 5-6 times
F. 7-8 times
G. $9-10$ times
H. 10-20 times
I. 21-50 times
J. over 50 times

6. Have any of your relationships resulted in cohabitation (living together for at least three months) with a member of the opposite sex?
E. none
F. 5
B. 1
G. 6
C. 2
H. 7
D. 3
I. 8
E. 4
J. 9 or more

7. What is your current marital status?
A. single, never married
B. married
C. married, now separated
D. divorced
E. widowed

8. How important is it for you to have a farily of your own, including a spouse and children?
A. extremely important
B. quite important
C. slightly important
(D. neither important or unimportant
E. slightly unimportant
F. quite unimportant
G. extremely unimportant

9. How many children do you have?
A. None (I have no children)
E. 4
B. 1
C. 2
F. 5
D. 3
G. 6
H. more than six 
10. How many intimate relationships have you had that lasted LESS than SIX (6) months?
A. None
B. One
C. Two
D. Three or Four
E. Five or Six
(F) Seven or Eight
G. Nine or Ten
H. Ten to Twenty
I. More than Twenty

11. How many of your intimate relationships have lasted LONGER than SIX (6) months?
(A.) None
E. Five or Six
B. One
F. Seven or Eight
C. Two
G. Nine or Ten
D. Three or Four
H. Ten to Twenty
I. More than Twenty

The following section has items regarding sexual activity, attitudes, and perspectives. Please respond to each item as accurately and as truthfully as possible. Remember, all responses are held in strict confidence.

12. How often (for the past year) did you engage in sexual intercourse or activity with another person?
A. more than once a day
B. about once every day
C. more than once a week
D. about once a week
E. about once a month
(F.) about once every three months
G. about once every six months
$\mathrm{H}$. once a year or less
I. I have never engaged in sexual intercourse or activity with another person.

13. Given the opportunity, how often would you DESIRE or like to have sexual intercourse or activity with another person?
A. more than once a day
B. about once every day
C. more than once a week
D. about once a week
E. about once a month
F. about once every three months
G. about once every six months
$\mathrm{H}$. once a year or less
I. I have never desired sexual intercourse or activity with another person.


14. How often do you masturbate?
A. more than once a day
B. about once every day
C. more than once a week
D. about once a week
E. about once a month
F. about once every three months
G. about once every six months
H. once a year or less
I. I have never masturbated.

15. Given the opportunity, how often would you like to masturbate?
A. more than once a day
B. about once every day
C. more than once a week
D. about once a week
E. about once a month
F. about once every three months
$G$. about once every six months
H. once a year or less
I. I have never wanted to masturbate.

16. In your entire life, how many PERSONS (sexual partners) have you ever had sex with?
A. None
F. $7-10$
B. One
G. 11-15
C. Two
H. $16-20$
D. 3-4
I. 21-30
E. $5-6$
J. more than thirty 
Each of the following questions relate to different aspects of human sexuality. Please answer each to the best of your ability and as honestly as possible.

77. At what age did you first have sexual intercourse?
A. age 12 or younger
B. 13
C. 14
D. 15
E. 16
F. 17
द. 18
NOTE: If you have never
H. 19
I. 20
J. age 21 or older had sex, please OMIT this item and go on to the next question.

78. How great is your desire to become a parent SOMETIME in your life?

NONE

WHATSOEVER

0 --- 1--$2-\cdots 3$ $4--5$ 6---- 7---- 8--- 9

79. How great is your desire to become a parent in the NEXT YEAR or so?

NONE

WHATSOEVER

VERY

MUCH SO

(9)-. 1 -

$2---3---4$

$4----5=--$

6---

7----

8---- 9

80. Considering your own sexual activities, how frequently do YOU use contraception (such as condoms, diaphragms, birth control pills, etc.)?

NEVER

RARELY

SOMETIMES

OFTEN

ALWAYS

$0-\cdots-1$ $1-\cdots$ 2---- 3 $4-\cdots-5$ $5----6$ 6---- 7--- $8-\cdots 9$ 
PLEASE MARK ALL RESPONSES FOR THIS SURVEY ON RESPONSE SHEET \# 2

The following section applies only to those people who have had sexual intercourse in the past twelve (12) months. If this does not apply to you, skip this section entirely. Remember, your responses are held in strict confidence. Do not put your name or indentifying information on this survey.

For each of the following birth control methods indicate those that you have used. If you use a particular method, please respond to the question regarding consistency of use of that method. If you do not use a particular method, respond "No" and go on the next method.

1. I, personally, have used birth control method in the past 12 months.
(A. Yes
B. No

If YES, continue. If, NO, skip to Question \# 20.

2. HORMONAL (BIRTH CONTROL PILLS):
A. Yes
B. No

3. If you answered "A. yes" above, please indicate how consistent your use of this method is:

$100 \% \quad 75 \% \quad 50 \% \quad \begin{gathered}\text { less than } \\ 25 \%\end{gathered}$
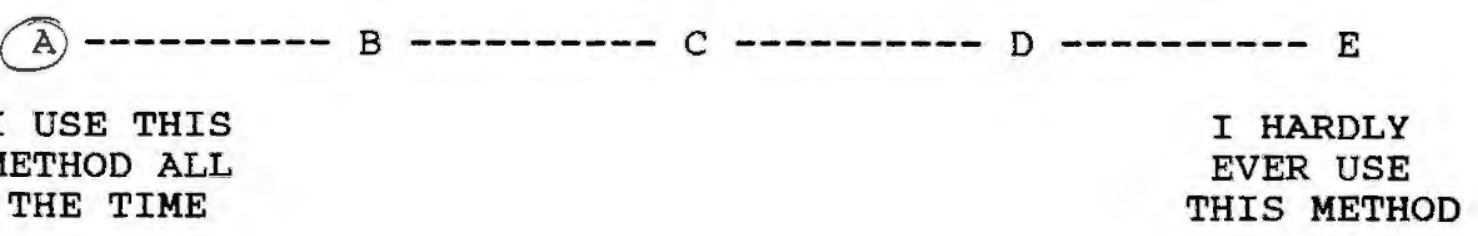

I USE THIS

METHOD ALL

EVER USE

THE TIME 
4. CONDOMS:

(A. Yes

B. No

5. If you answered "A. yes" above, please indicate how consistent your use of this method is:

$100 \%$

$75 \%$

$50 \%$

25

less than 25 웅

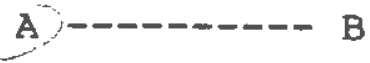

C

D

E

I USE THIS

METHOD ALL

I HARDLY

EVER USE

THE TIME

THIS METHOD

6. DIAPHRAGM :

A. Yes
B. No

7. If you answered "A. Yes" above, please indicate how consistent your use of this method is:
$100 \%$
$75 \%$
50 움
25 客 $25 \%$

less than

A $---------D B$

C

$\mathrm{D}$

E

I USE THIS

METHOD ALL

I HARDLY

EVER USE

THE TIME

THIS METHOD

8. IUD (INTRAUTERINE DEVICE):

A. Yes

B. No

9. If you answered "A. yes" above, please indicate how consistent your use of this method is:

$100 \%$

75 웅

50 영

25 웅

less than 25 영

A $---------B$

C $---------D$

I USE THIS

METHOD ALL

I HARDLY

EVER USE

THE TIME

THIS METHOD 
10. STERILIZATION (vasectomy, tubal ligation):
A. Yes
B. : No

11. If you answered "A. yes" above, please indicate how consistent your use of this method is:

$\begin{array}{lllll}100 \% & 75 \% & 50 \% & 25 \% & 25 \%\end{array}$

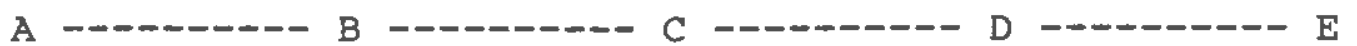

I USE THIS

METHOD ALL

THE TIME
I HARDLY

EVER USE

THIS METHOD

12. SPONGE ("Today" or other contraceptive sponges):
A. Yes
B. No

13. If you answered "A. yes" above, please indicate how consistent your use of this method is:
$100 \%$
$75 \%$
$50 \%$
$25 \%$ 25 웅

less than

A

C

D - - - - - - $E$

I USE THIS

METHOD ALL

I HARDLY

THE TIME

EVER USE

THIS METHOD

14. WITHDRAWAL (Coitus interruptus):
A. Yes
B. No

15. If you answered "A. yes" above, please indicate how consistent your use of this method is:
$100 \%$
$75 \%$
$50 \%$
25 \% 258

less than

A

$\mathrm{B}$

C

D

E

I USE THIS

I HARDLY

METHOD ALL

EVER USE

THE TIME

THIS METHOD 
16. RHYTHM (natural family planning methods):
A. Yes
(B) No

17. If you answered "A. yes" above, please indicate how consistent your use of this method is:

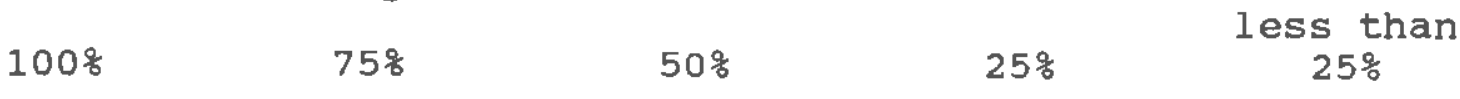

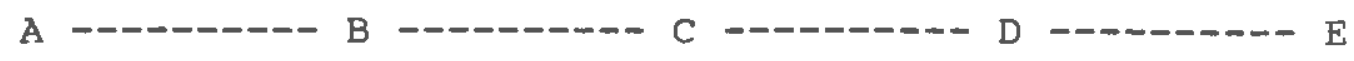

I USE THIS

METHOD ALL

THE TIME
I HARDLY EVER USE THIS METHOD

18. FOAM (Delfon, Conceptrol):
A. Yes
B. No

19. If you answered "A. yes" above, please indicate how consistent your use of this method is:
$100 \%$
$75 \%$
$50 \%$
25 움 $25 \%$

less than

A

B

C

D - - - - - $E$

I USE THIS

METHOD ALL

I HARDLY

THE TIME

EVER USE

THIS METHOD 


\section{ATTITUDES TOWARD CASUAL SEX}

For some people, having sex with an unfamiliar person is a desirable notion, for others it is not. Consider the possibility that you find yourself with the opportunity to have sexual relations with an unfamiliar person.

For each of the following items, indicate HOW YOUR DECISION to have sex with an unfamiliar person might be influenced. That is, HOW IMPORTANT is each of the following in your decision to have sex with a stranger?

Please respond as honestly and carefully as possible. Remember, all responses are confidential and cannot be traced to you.

Again, please indicate HOW IMPORTANT. .

1. I know something about the person

NOT AT ALL

IMPORTANT

$\begin{array}{llllllll}0 & 1 & 2 & 3 & 4 & 5 & 6 & 7\end{array}$

849

EXTREMELY

IMPORTANT

2. My friends know something about the person

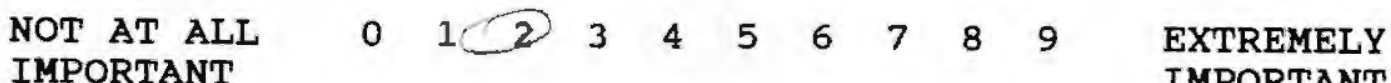
IMPORTANT

IMPORTANT

3. It is a "blind date" arranged by good friends

$\begin{array}{llllllllllll}\text { NOT AT ALL } & 0 & 1 & 2 & 3 & 4 & 5 & 6 & 7 & 8 & 9 & \text { EXTREMELY }\end{array}$ IMPORTANT IMPORTANT

4. We meet in a familiar environment/locale

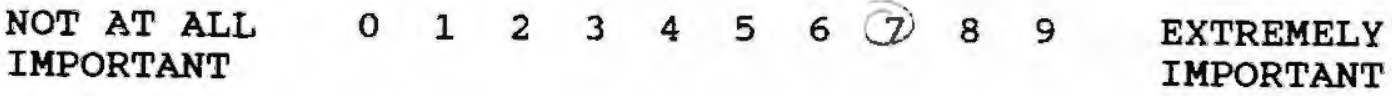

5. We meet in a strange environment/locale

$\begin{array}{llllllllllll}\text { NOT AT ALL } & 0 & 1 & 2 & 3 & 4 & 5 & 6 & 7 & 8 & 9 & \text { EXTREMELY }\end{array}$ IMPORTANT IMPORTANT 
As before, for each of the following, indicate How IMPORTANT each factor is in your decision to have sex with an unfamiliar person.

6. I am alone when we meet

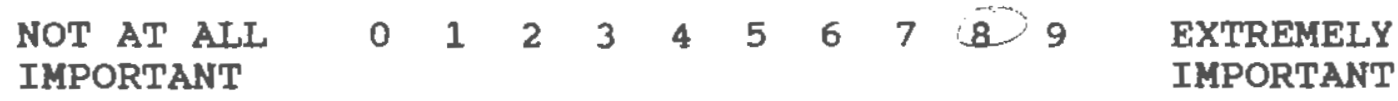

7. I am with friends when we meet

$\begin{array}{lllllllllllll}\text { NOT AT ALL } & 0 & 1 & 2 & 3 & \mathbf{4} & 5 & 6 & 7 & 8 & 9 & \text { EXTREMELY }\end{array}$ IMPORTANT IMPORTANT

8. I am in control of the situation

$\begin{array}{llllllllllll}\text { NOT AT ALL } & 0 & 1 & 2 & 3 & 4 & 5 & 6 & 7 & 8 & 9 & \text { EXTREMELY }\end{array}$ IMPORTANT $\quad$ IMPORTANT

9. The desire to have sex with this person is my idea $\begin{array}{llllllllllll}\text { NOT AT ALL } & 0 & 1 & 2 & 3 & 4 & 5 & 6 & 7 & 8 & 9 & \text { EXTREMELY }\end{array}$ IMPORTANT $\quad$ IMPORTANT

10. The desire to have sex with this person is his/her idea $\begin{array}{lllllllllllll}\text { NOT AT ALL } & 0 & 1 & 2 & 3 & 4 & 5 & 6 & 7 & 8 & 9 & \text { EXTREMELY }\end{array}$ IMPORTANT 
CONCERN SECTION

For each of the following, indicate the degree of CONCERN you might have with regard to having sex with an unfamiliar person. That is, how CONCERNED are you with each of the following aspects associated with having sex with a stranger?

Please respond as honestly and as carefully as possible. Remember, all responses are confidential and cannot be traced to you.

Again, please indicate your degree of CONCERN. . .

11.

The possibility that I may be physically harmed or beaten (assaulted, but not in a sexual way)

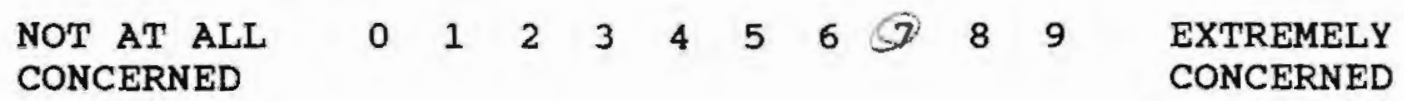

12. I could get a curable venereal disease
NOT AT ALL
$\begin{array}{llllllllll}0 & 1 & 2 & 3 & 4 & 5 & 6 & 7 & (8) & 9\end{array}$
EXTREMELY CONCERNED
CONCERNED

13. I could get an incurable venereal disease or AIDS $\begin{array}{llllllllllll}\text { NOT AT ALL } & 0 & 1 & 2 & 3 & 4 & 5 & 6 & 7 & 8 & 9 & \text { EXTREMELY }\end{array}$ CONCERNED CONCERNED

14. The possibility of pregnancy exists.

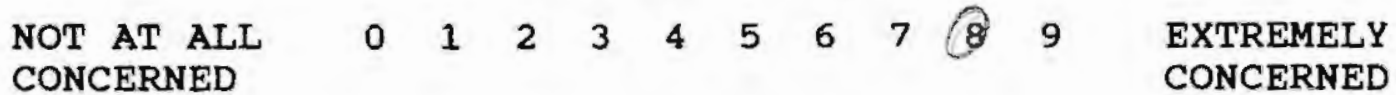

15. My friends will think the stranger is undesirable

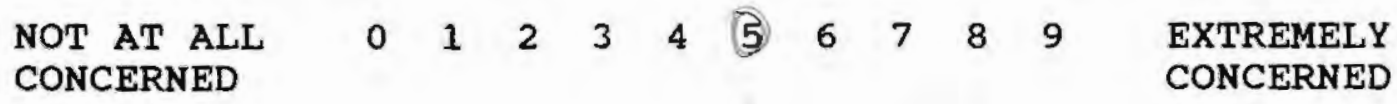

16. The sexual activity might simply be unenjoyable

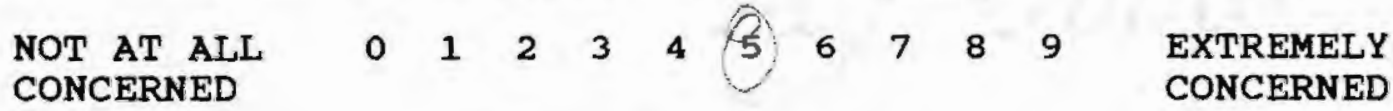


Again, for each of the following, indicate the degree of CONCERN you might have with regard to having sex with an unfamiliar person. That is, how CONCERNED are you with each of the following aspects associated with having sex with a stranger?

17. My family will think I'm acting irresponsibly

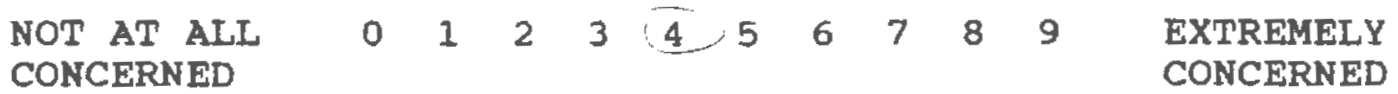

18. My family will think I'm acting immorally

$\begin{array}{llllllllllll}\text { NOT AT ALI } & 0 & 1 & 2 & 3 & 4 & 5 & 6 & 7 & 8 & 9 & \text { EXTREMELY }\end{array}$ CONCERNED

CONCERNED

CONTINUED ON NEXT PAGE 


\section{CATEGORIES}

For each of the following scales please indicate your degree of feelings/opinions in response to the following statement;

"Overall, I consider the opportunity to have sex with an unfamiliar person":

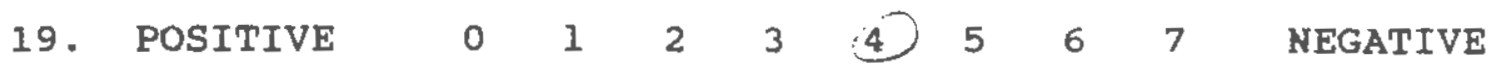

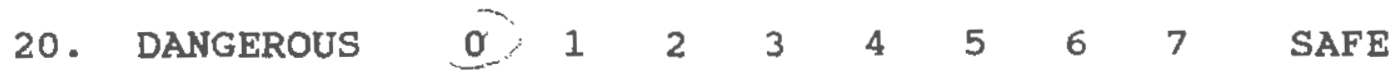

$\begin{array}{lllllllllll}\text { 21. ROUTINE } & 0 & 1 & 2 & 3 & 4 & 5 & 6 & 7 & \text { DARING }\end{array}$

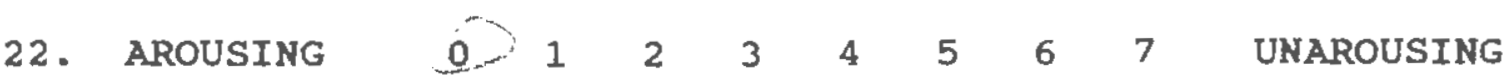

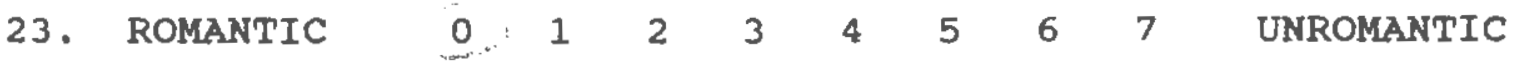

24. DESIRABLE $\begin{array}{lllllllll}0 & 1 & 2 & 3 & 4 & 5 & 6 & 7 & \text { UNDESIRABLE }\end{array}$

$\begin{array}{lllllllllll}\text { 25. KINKY } & 0 & 1 & 2 & 3 & 4 & 5 & 6 & 7 & \text { ORDINARY }\end{array}$

END OF THIS QUESTIONNAIRE. THANK YOU FOR YOUR PARTICIPATION. PLEASE WAIT FOR FURTHER INSTRUCTIONS. 

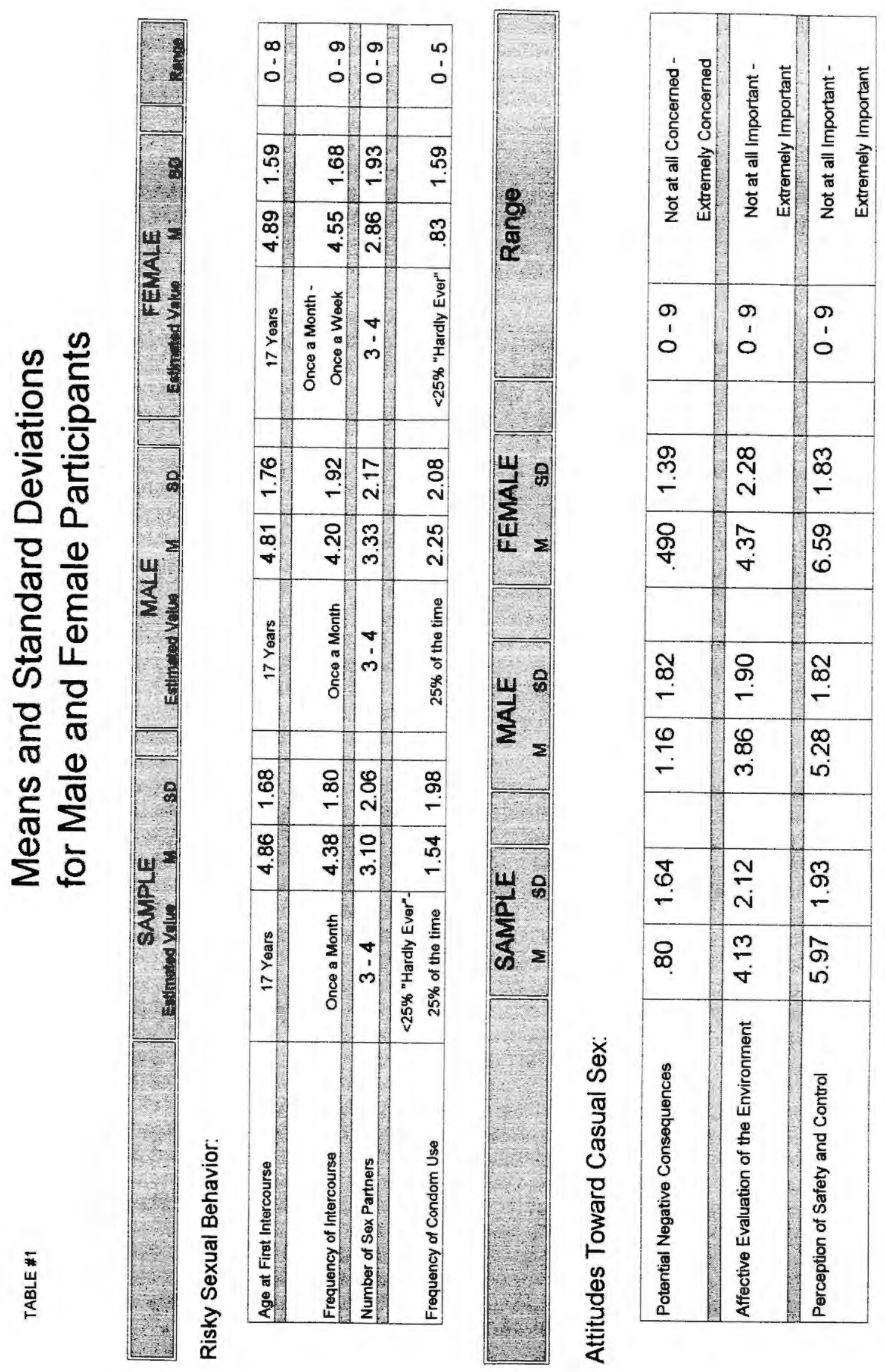


\section{Varimax Loading of Items of Attitudes Toward Casual Sex Survey}

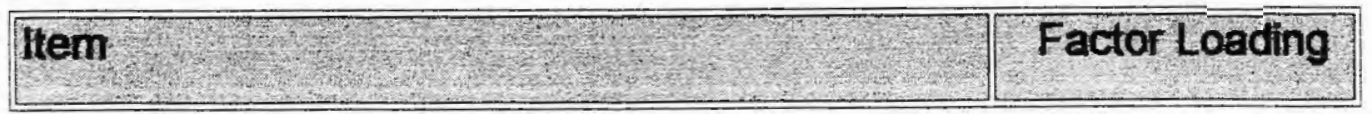

\begin{tabular}{|c|c|}
\hline \multicolumn{2}{|l|}{ 1. Potential Negative Consequences } \\
\hline Possibiltiy of physical harm & .79 \\
\hline Possibility of contracting curable venereal disease & .91 \\
\hline Possibility of contracting incurable venereal disease / AIDS & .91 \\
\hline Possibility of pregnancy & .76 \\
\hline Eigenvalue $=3.76$ & $34.2 \%$ of the variance \\
\hline \multicolumn{2}{|l|}{ 2. Perception of Safety and Control } \\
\hline Knowledge of potential casual sex partner & .68 \\
\hline Friends' knowledge of potential casual sex partner & .70 \\
\hline Control of the casual sex situation & .70 \\
\hline Initiation of casual sex & .72 \\
\hline Eigenvalue $=2.14$ & $19.4 \%$ of the variance \\
\hline \multicolumn{2}{|l|}{ 3. Affective Evaluation of the Environment } \\
\hline Potential casual sex partner is met in strange environment & .80 \\
\hline Alone when potential casual sex partner is met & .82 \\
\hline With friends when potential casual sex partner is met & .62 \\
\hline Eigenvalue $=1.09$ & $9.9 \%$ of the variance \\
\hline 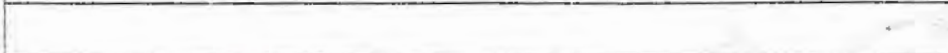 & \\
\hline
\end{tabular}




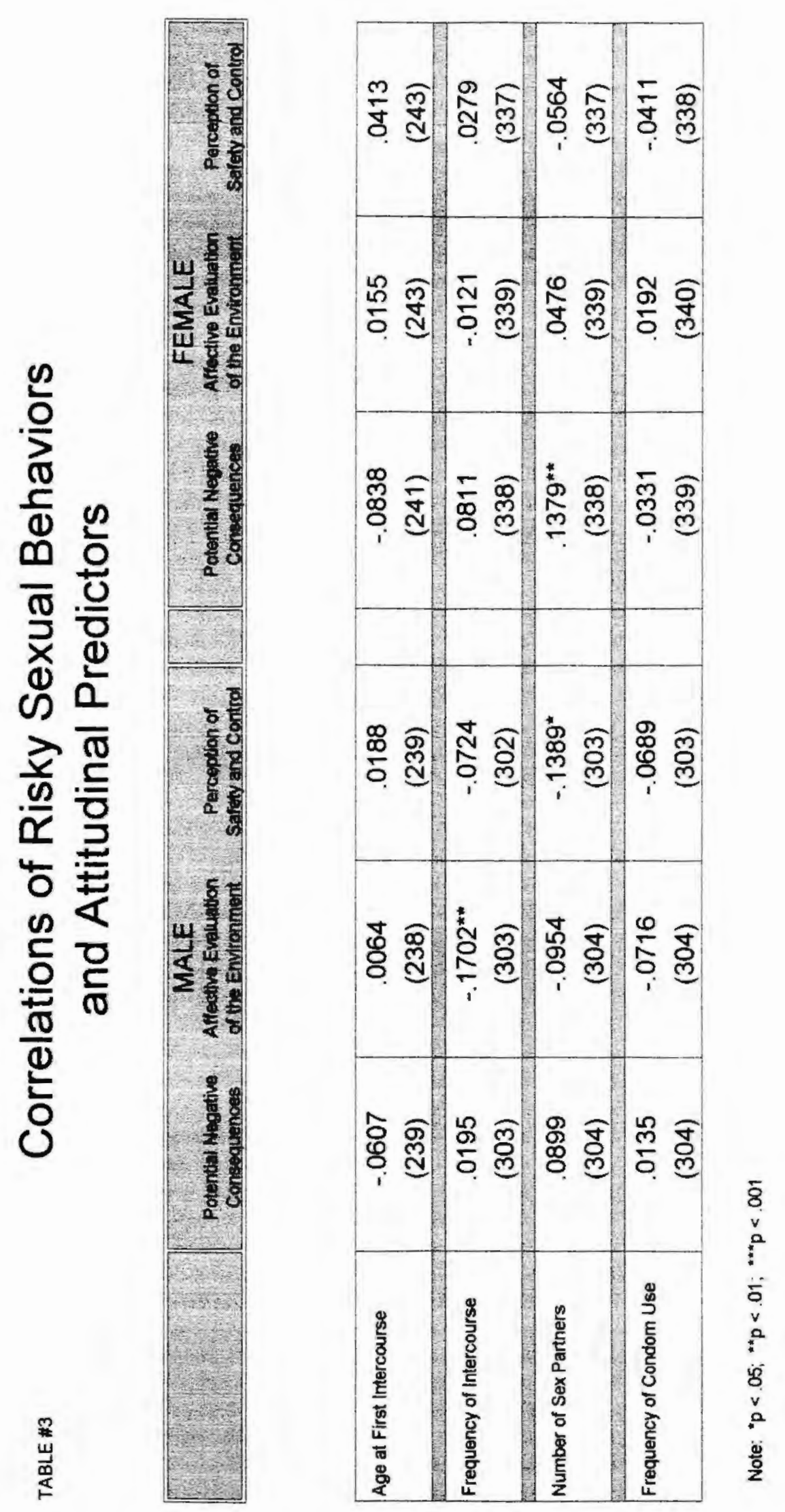




\section{Relationships Between Risky Sexual Behaviors and Attitudinal Predictors}

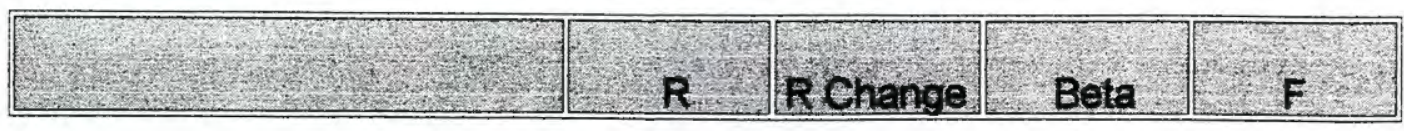

Age at First Intercourse:

\begin{tabular}{|l|c|c|c|c|}
\hline Gender & .04 & .00 & .04 & .83 \\
\hline \hline Potential Negative Consequences & .08 & .01 & -.07 & 2.33 \\
\hline \hline Interaction 1 & .08 & .00 & -.03 & .22 \\
\hline Gender & .04 & .00 & .04 & .80 \\
\hline Affective Evaluation of the Environment & .04 & .00 & .01 & .04 \\
\hline Interaction 2 & .04 & .00 & .00 & .00 \\
\hline Gender & .04 & .00 & .04 & .95 \\
\hline Perception of Safety and Control & .05 & .00 & .03 & .28 \\
\hline Interaction 3 & .05 & .00 & .00 & .00 \\
\hline
\end{tabular}

Frequency of Intercourse:

\begin{tabular}{|l|c|c|c|c|}
\hline Gender & .01 & .00 & .01 & .12 \\
\hline \hline Potential Negative Consequences & .05 & .00 & .05 & 1.46 \\
\hline \hline Interaction 1 & .06 & .00 & .05 & .81 \\
\hline Gender & .02 & .00 & .02 & .22 \\
\hline Affective Evaluaton of the Environment & .08 & .01 & -.08 & $4.08^{\star}$ \\
\hline \hline Interaction 2 & .12 & .00 & .23 & $4.69^{\star}$ \\
\hline Gender & .02 & .00 & .02 & .18 \\
\hline Perception of Safety and Control & .03 & .00 & -.02 & .33 \\
\hline \hline Interaction 3 & .05 & .00 & .17 & 1.25 \\
\hline
\end{tabular}

Note: $" \mathrm{p}<.05 ; " * \mathrm{p}<.01 ; \quad * * * 0.001$ 
TABLE $\$ 4$ continued

\section{Relationships Between Risky Sexual Behaviors and Attitudinal Predictors}

\section{R R Change Beta}

Number of Sex Partners:

\begin{tabular}{|l|c|c|c|c|}
\hline Gender & .14 & .02 & -.14 & $13.44^{\star \star \star}$ \\
\hline Potential Negative Consequences & .18 & .01 & .11 & $7.86^{\star \star}$ \\
\hline Interaction 1 & .18 & .00 & .04 & .68 \\
\hline Gender & .14 & .02 & -.14 & $13.30^{\star \star \star}$ \\
\hline \hline Affective Evaluaton of the Environment & .14 & .00 & -.02 & .20 \\
\hline \hline Interaction 2 & .16 & .01 & .20 & 3.65 \\
\hline Gender & .14 & .02 & -.14 & $12.96^{\star \star \star}$ \\
\hline Perception of Safety and Control & .17 & .01 & -.10 & $6.06^{\star \star}$ \\
\hline \hline Interaction 3 & .18 & .00 & .19 & 1.59 \\
\hline
\end{tabular}

Frequency of Condom Use:

\begin{tabular}{|l|c|c|c|c|}
\hline Gender & .33 & .11 & -.33 & $78.66^{\star \star *}$ \\
\hline Potential Negative Consequences & .33 & .00 & -.00 & .01 \\
\hline \hline Interaction 1 & .33 & .00 & -.03 & .33 \\
\hline Gender & .33 & .11 & -.33 & $77.56^{\star \star \star}$ \\
\hline Affective Evaluaton of the Environment & .33 & .00 & -.03 & .48 \\
\hline Interaction 2 & .34 & .00 & .13 & 1.75 \\
\hline Gender & .32 & .11 & -.32 & $73.92^{\star * \star}$ \\
\hline \hline Perception of Safety and Control & .33 & .00 & -.06 & 2.06 \\
\hline Interaction 3 & .33 & .00 & .08 & .33 \\
\hline
\end{tabular}

Note: ${ }^{*} p<.05 ;{ }^{* *} p<.01 ;{ }^{* * *} p<.001$ 


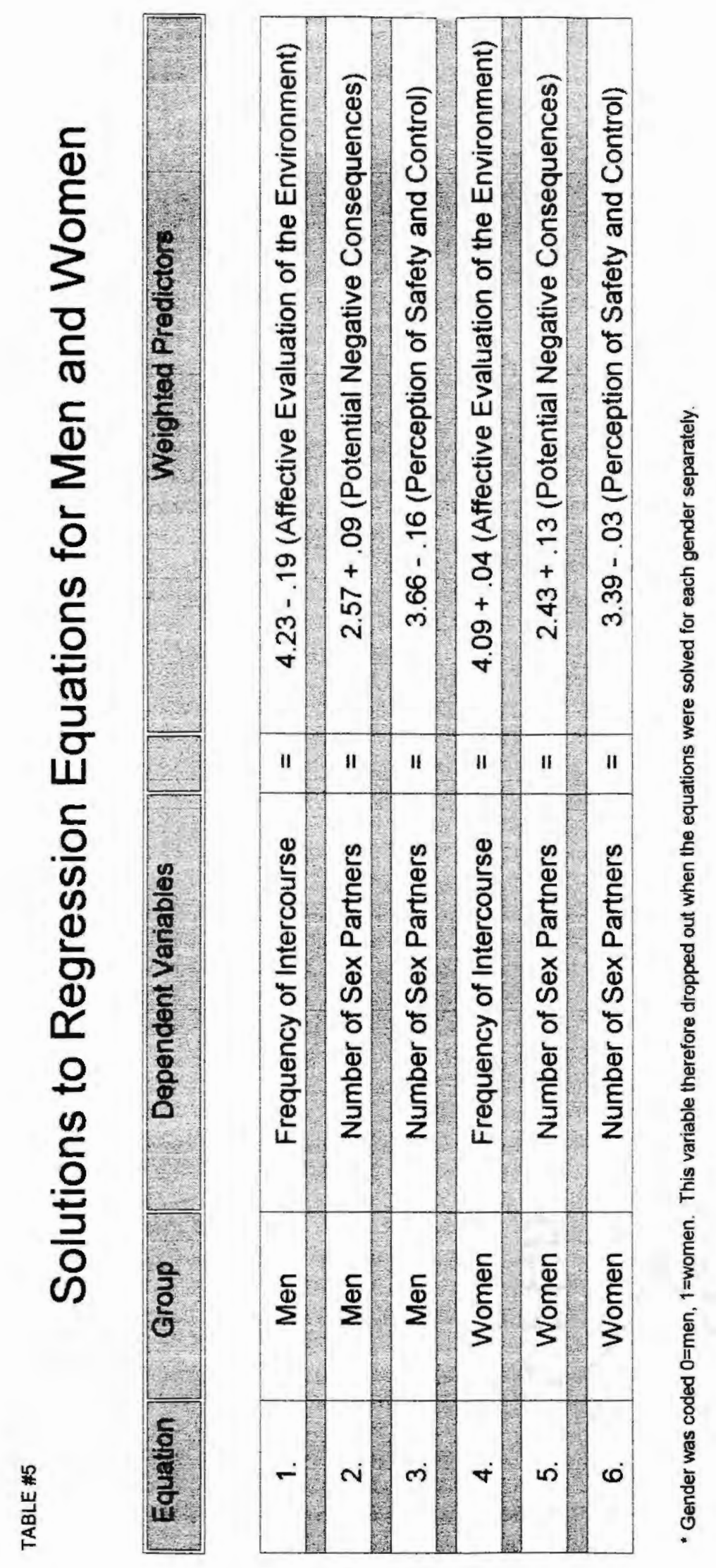



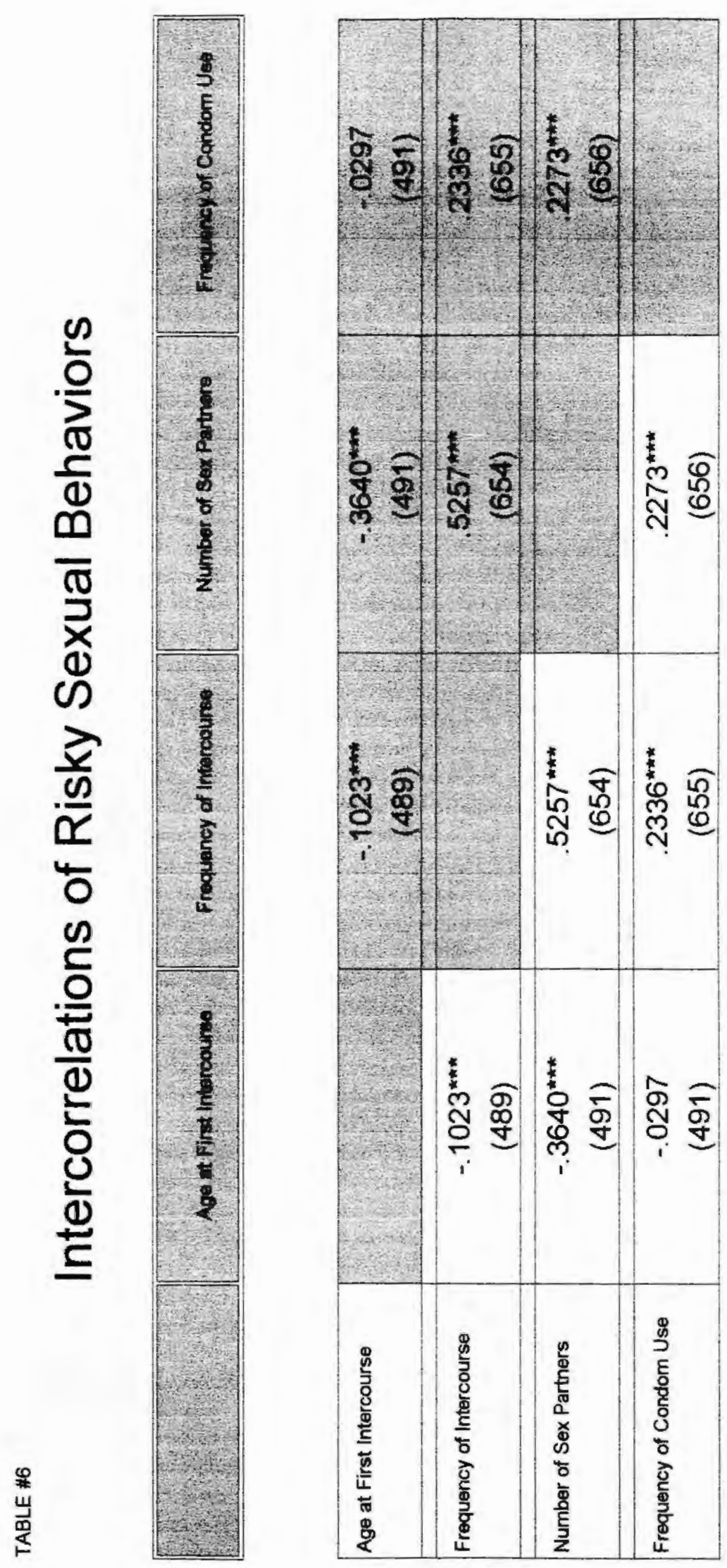

$\overline{8}$

ำ

\begin{tabular}{|c|c|c|c|}
\hline 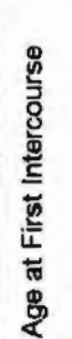 & 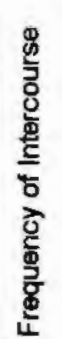 & 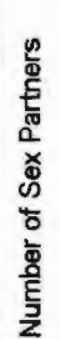 & 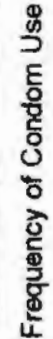 \\
\hline
\end{tabular}

$\div$

$\checkmark$

ஜ்

v

혼 


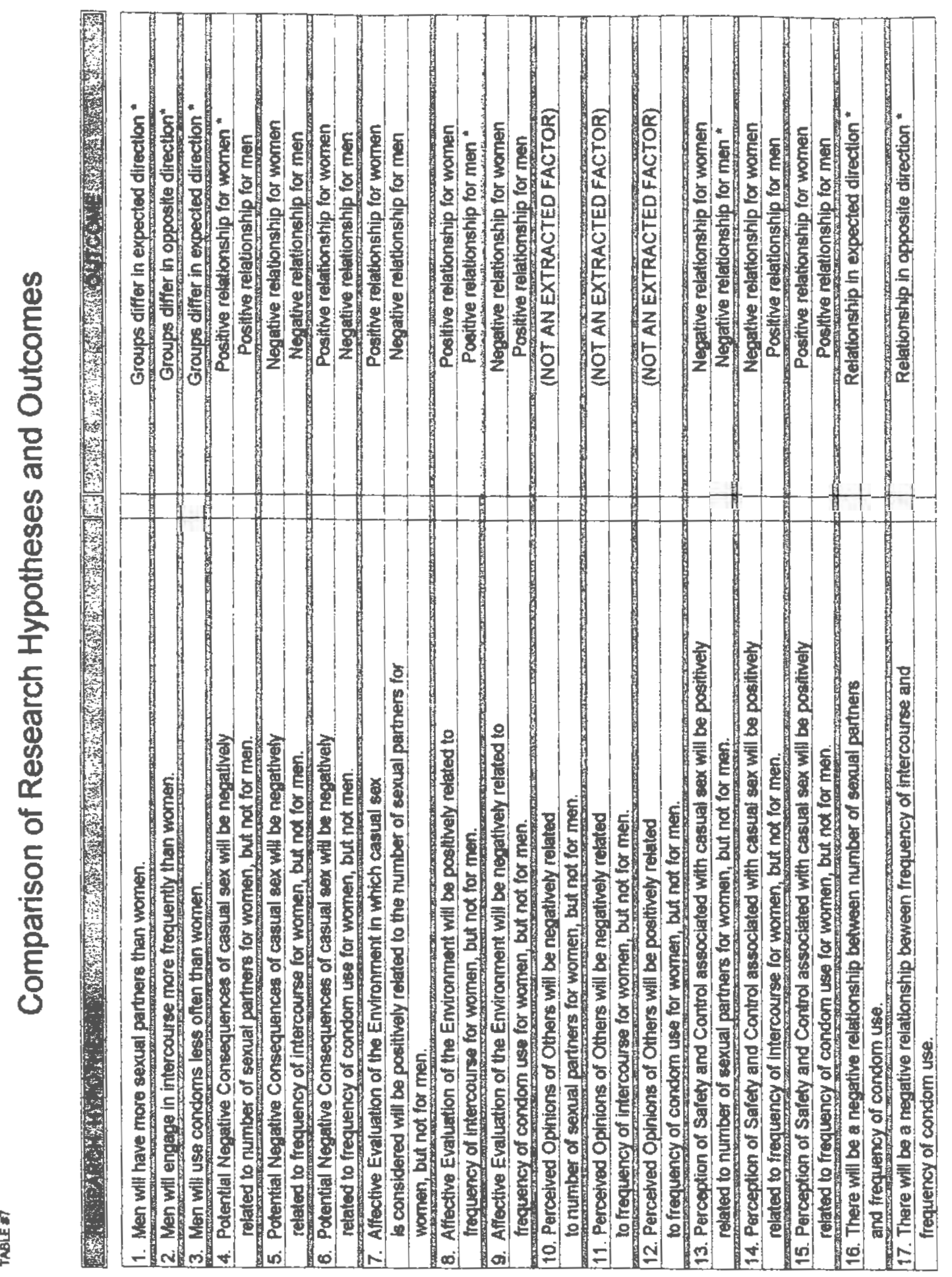




\section{Frequency of Intercourse}

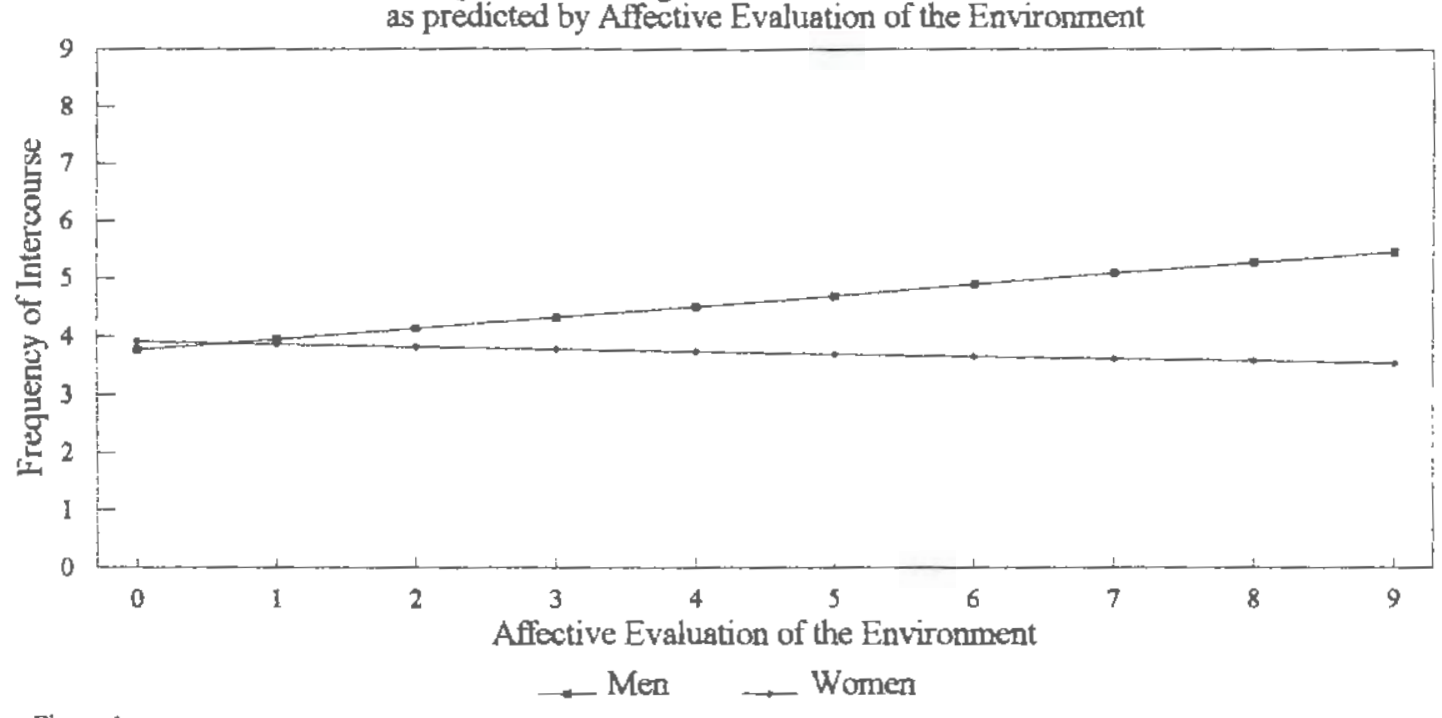

Figure 1 


\section{Number of Sex Partners}

as predicted by Potential Negative Consequences

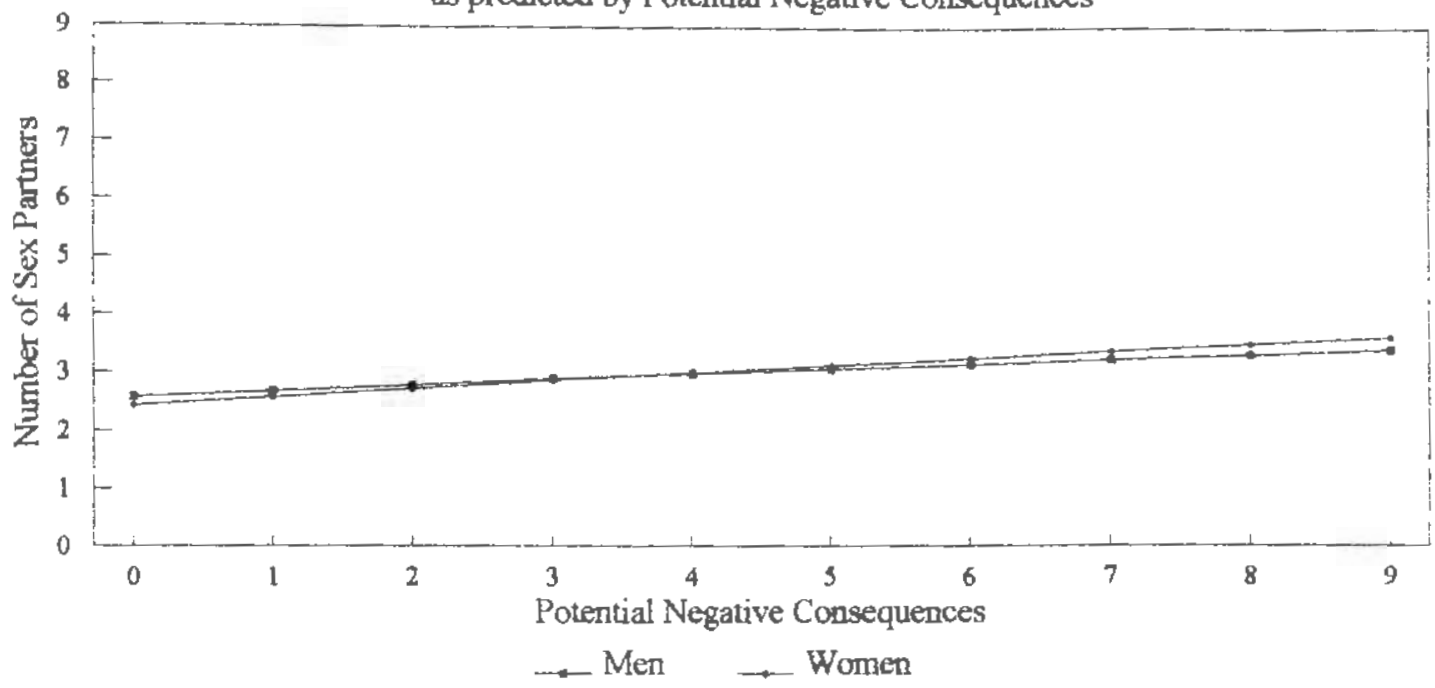

Figure 2

Number of Sex Partners

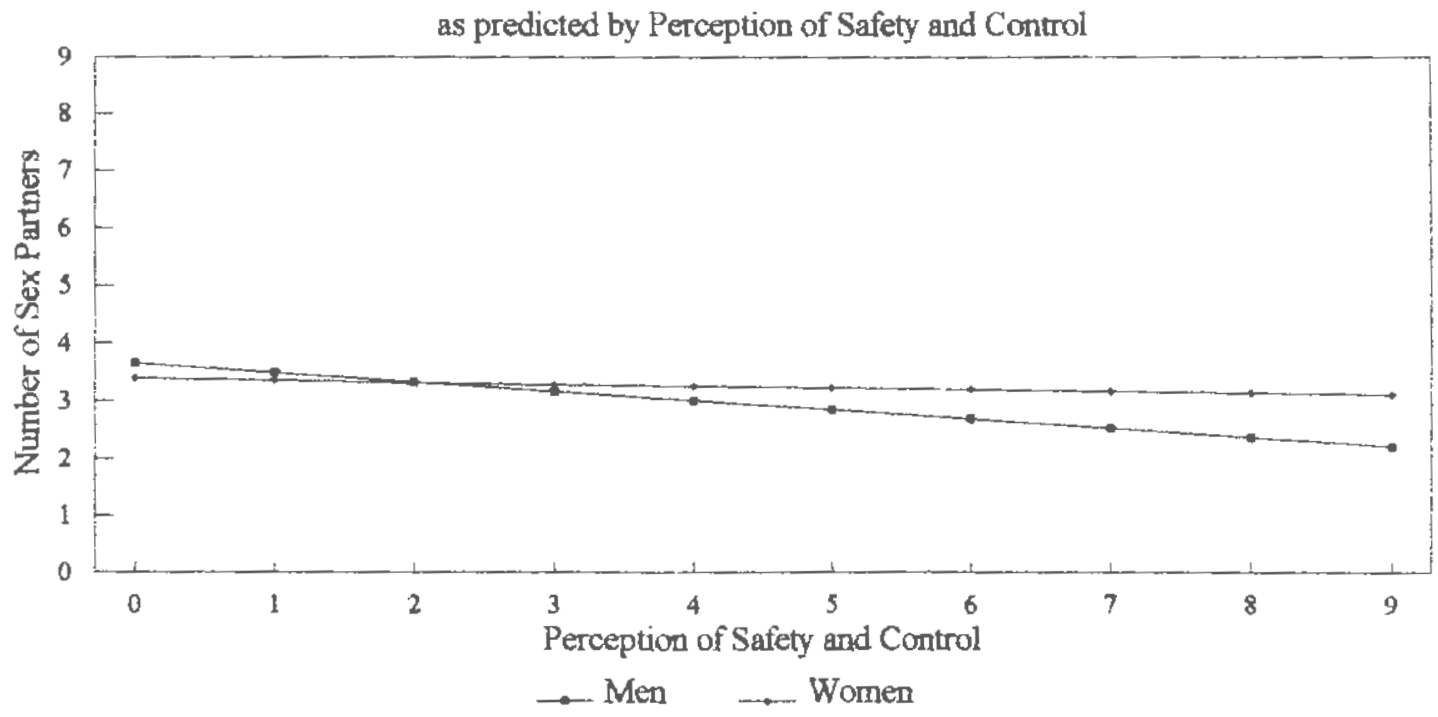

Figure 3 


\section{Bibliography}

AIDS virus infects 0.38 of college students. (1988, November 3). The San Diego Union, p. A3.

Baldwin, J., \& Baldwin, J. (1988). Factors affecting AIDSrelated sexual risk-taking behavior among college students. The Journal of Sex Research, 25(2), 181-196. Biglan, A., Metzler, C., Wirt, R., Ary, D., Noell, J., Ochs, L., French, C., \& Hood, D. (1990). Social and behavioral factors associated with high-risk sexual behavior among adolescents. Journal of Behavioral Medicine, 13 $(3), 245-261$.

Bishop, P., \& Lipsitz, A. (1991). Sexual behavior among college students in the AIDS era: a comparative study. Journal of Psychology \& Human Sexuality, 3(2), 35-52.

Cattell, R.B. (1986). The scree test for the number of

factors. Multivariate Behavioral Research, 1, 245-279. Carroll, L. (1991). Gender, knowledge about AIDS, reported behavioral change, and the sexual behavior of college students. Journal of American College Health, 40, 5-12. Centers for Disease Control (April, 1992). HIV/AIDS quarterly surveillance report. National Center for Infectious Diseases, $1-18$.

Clark, R. (1990). The impact of AIDS on gender differences in willingness to engage in casual sex. Journal of Applied Social Psychology, 20(9), $771-782$.

Curran, J.W., Jaffe, H.W., Hardy, A.M., Morgan, W.M., Selik, R.M. \& Dondero, T.J. (1988). Epidemiology of HIV 
infection and AIDS in the United States. Science, 239, $610-616$

Cvetkovich, G. , \& Grote, B. (1980). Psychological development and the social problem of teenage illegitimacy. In $\mathrm{C}$. Chilman (Ed.), Adolescent pregnancy and childbearing: Findings from research (Pp. 15-41). Washington, DC: U.S. Department of Health and Human Services. DeBuono, B., Zinner, S., Daamen, M., \& McCormack, W. (1990). Sexual behavior of college women in 1975, 1986 and 1989. The New England Journal of Medicine, 322(12), 821-825. DiClemente, R., Forrest, K., \& Mickler, S. (1990). College students' knowledge and attitudes about AIDS and changes in HIV-preventive behaviors. AIDS Education and Prevention, 2(3), 201-212.

Eagly, A.H., \& Chaiken, S. (1992). The psychology of attitudes. San Diego, CA: Harcourt Brace Janovich. Edgar, T., Freimuth, V., \& Hammond, S. (1988). Communicating the AIDS risk to college students: the problem of motivating change. Health Education Research, 3(1), 5965.

Fishbein, M., \& Ajzen, I. (1975). Belief, attitude, intention and behavior: An introduction to theory and research. Reading, MA: Addison-Wesley.

Fisher, J., \& Misovich, S. (1990). Evolution of college students" AIDS-related behavioral responses, attitudes, knowledge, and fear. AIDS Education and prevention, $\underline{2}(4), 322-337$. 
Fisher, W., Byrne, D., Edmunds, M., Miller, C., Kelley, K., \& White, L. (1979). Psychological and situation-specific correlates of contraceptive behavior among university women. Journal of Sex Research, 15, 38-55.

Foreit, K., \& Foreit, J. (1978). Correlates of contraceptive behavior among unmarried U.S. college students. studies in Family planning, 9, 169-175.

Geis, B.D. \& Gerrard, M. (1984). Predicting male and female contraceptive behavior: a discriminant analysis of groups high, moderate and low in contraceptive effectiveness. Journal of Personality and Social psychology, $\underline{46}(3), 669-680$.

Gfellner, B. (1988). Relations between sexual attitudes, gender, and sexual behaviour concepts of older adolescents. Journal of Adolescent Research, 3(3-4), $305-316$.

Gray, L., \& Saracino, M. (1989). AIDS on campus: a preliminary study of college students' knowledge and behaviors, Journal of Counseling \& Development, 68, 199202 .

Guadagnoli, E., \& Velicer, W.F. (1988). Relation of sample size to the stability of component patterns. Psychological Bulletin, $103(2), 265-275$.

Harlow, L.L., Grimley, D., Quina, K., \& Morokoff, P. (1992, March). Behavioral, interpersonal and psycho-attitudinal predictors of HIV-risk in women. Paper presented at the meeting of the Society for Behavioral Medicine, New York 
City, New York.

Inazu, J.K., \& Fox, G.I. (1980). Maternal influence on the sexual behavior of teenage daughters. Journal of Family Is sues, $1,81-102$.

Ishii-Kuntz, M. (1988). Acquired Immune Deficiency Syndrome and sexual behavior changes in a college student sample. Sociology and Social Research, 73(1), 13-15.

Jessor, R. \& Jessor, S.L. (1977). Problem behavior and psychosocial development. New York: Academic Press.

Jorgensen, S.R., King, S.L. \& Torrey, G.A. (1980). Dyadic and social network influences on adolescent exposure to pregnancy risk. Journal of Marriage and the Family, 42 , $141-155$.

Kahn, J., Smith, K., \& Roberts, E. (1984). Familial communication and adolescent sexual behavior (Final report to the office of Adolescent Pregnancy Programs). Cambridge, MA: American Institutes for Research. Kantrowitz, B., Hager, M., Cowley, G., Beachy, L., Rossi, M., Craffey, B., Annin, P., \& Crandall, R. (1992, August 3). Teenagers and AIDS. Newsweek, pp. 45-50. Katzman, E., Mulholland, M., \& Sutherland, E. (1988). College students and AIDS: a preliminary survey of knowledge, attitudes and behavior. Journal of American College Health, 37(3), 127-130.

LaPiere, R.T. (1934). Attitudes versus actions. Social Forces, $13,230-237$.

Loos, C., \& Bowd, A. (1989). AIDS-related behaviour change, 
knowledge and opinions among first year university students. Canadian Journal of Counselling, 233(3), 288295.

McDermott, R., Hawkins, M., Moore, J., \& Cittadino, S. (1987). AIDS awareness and information sources among selected university students. Journal of American College Health, 35 (5), 222-226.

Morokoff, P. (1986). Volunteer bias in the psychophysiological study of female sexuality. Journal of Sex Research, 22(1), 35-51.

Morokoff, P. (1990). Sex and infertility. Unpublished manuscript.

Morokoff, P.J., Grimley, D., Harlow, L.L., \& Quina, K. (1992, August). AIDS prevention in women: Behavioral change efforts and public policy. In S.M. Czajkowski (Chair), Biobehavioral influences on women's health: Research and policy perspectives. Symposium presented at the annual meeting of the American Psychological Association, Washington, D.C.

Mosher, W.D. (1985). Reproductive impairments in the United States, 1965-1982. Demography, 22, 415-430.

Olson, J.M., \& Zanna, M.P. (1993). Attitudes and attitude change. Annual Review of Psychology, 44, 117-154. Person, E.S., Terestman, N., Myers, W.A., Goldberg, E.L., \& Salvadori, C. (1989). Gender differences in sexual behaviors and fantasies in a college population. Journal of Sex \& Marital Therapy, 15(3), 187-198. 
Sack, A.T., Billingham, R.E., \& Howard, R.D. (1985). Premarital contraceptive use: a discriminant analysis approach. Archives of Sexual Behavior, 14(2), 165-182. Schuman, H. \& Johnson, M.P. (1976). Attitudes and behavior. Annual Review of Sociology, 2, 161-207.

Severn, J. (1990). College students and condoms, AIDS and attitudes. College Student Journal, 24(3), 296-306. Simkins, L., \& Eberhage, M. (1984). Attitudes toward AIDS, herpes II, and toxic shock syndrome. Psychological Reports, 55, $779-786$.

Spees, E. (1987). College students' sexual attitudes and behaviors, 1974-1985: a review of the literature. Journal of College Student Personnel, 135-140.

Strunin, L., \& Hingson, R. (1987). Acquired immunodeficiency syndrome and adolescents: knowledge, beliefs, attitudes, and behaviors. pediatrics, 79(5), 825-828.

Sunenblick, M.B. (1988). The AIDS epidemic: sexual behaviors of adolescents. Smith College studies in Social Work, $\underline{59}(1), 21-37$.

Thurman, Q.C., Franklin, K.M. (1990). AIDS and college health: knowledge, threat, and prevention at a northeastern university. College Health, 38, 179-184. Udry, J.R. \& Billy, J.O.G. (1987). Initiation of coitus in early adolescence. American Sociological Review, 52 , $341-855$

Velicer, W.F., \& Fava, J.L. (1993). The effects of variable and subject sampling on factor pattern recovery. 
Manuscript submitted for publication.

Whitley, B.E. Jr., \& Hern, A.L. (1991). Perceptions of vulnerability to pregnancy and the use of effective contraception. Personality and Social Psychology Bulletin, 17(1), 104-110.

Wicker, A.W. (1969). Attitudes versus actions: the relationship of verbal and overt behavior responses to attitude objects. Journal of Social Issues, 25(4), 41 78 .

Wilson, S.M. \& Medora, N.P. (1990). Gender comparisons of college students' attitudes toward sexual behavior. Adolescence, 2 $\underline{5}(99), 615-627$.

Zelnik, M., Kantner, J.F., \& Ford, K. (1981). Sex and pregnancy in adolescence (Sage Library of Social Research, Vol. 133). Beverly Hills: Sage. 